\title{
Optimal Fiscal and Monetary Policy in Customer Markets ${ }^{* \dagger}$
}

\author{
David M. Arseneau ${ }^{\ddagger} \quad$ Ryan Chahrour $\S$ \\ Federal Reserve Board Boston College \\ Sanjay K. Chugh ฯ \\ Boston College
}

Kiel Institute for the World Economy

Alan Finkelstein Shapiro ॥

Universidad de los Andes

First Draft: July 2007

This Draft: November 18, 2013

\begin{abstract}
This paper presents a model in which some goods trade in "customer markets." In these markets, advertising plays a critical role in facilitating long-lived relationships. We estimate both policy and non-policy parameters of the model (which includes New-Keynesian frictions) on U.S. data, including advertising expenditures. The estimated parameters imply a large congestion externality in the pricing of customer market goods. This pricing inefficiency motivates the analysis of optimal policy. When the planner has access to a complete set of taxes and chooses them optimally, fiscal policy eliminates the externalities with large adjustments in the tax rates that operate directly in customer markets; labor tax volatility remains low. If available policy instruments are constrained to the interest rate and labor tax, then the latter displays large and procyclical fluctuations, while the implications for monetary policy are largely unchanged from the model with no customer markets. JEL Classification: E30, E50, E61, E63
\end{abstract}

${ }^{*}$ We thank the editor and the referees for helpful advice and suggestions. We thank for comments seminar and conference participants at Duke University, the Federal Reserve Bank of Philadelphia, the 2008 Midwest Macro Meetings (Philadelphia), the 2008 SED Meetings (Boston), and the 2009 Econometric Society Summer Meetings (Boston).

${ }^{\dagger}$ The views expressed here are solely those of the authors and should not be interpreted as reflecting the views of the Board of Governors of the Federal Reserve System or of any other person associated with the Federal Reserve System.

${ }^{\ddagger}$ email address: david.m.arseneau@frb.gov.

§email address: ryan.chahrour@bc.edu.

๑ email address: sanjay.chugh@bc.edu.

" email address: alanfshapiro@gmail.com. 


\section{Contents}

1 Introduction $\quad 1$

2 The Economy $\quad 3$

2.1 An Overview of Goods Trade in the Model . . . . . . . . . . . . . . . . 3

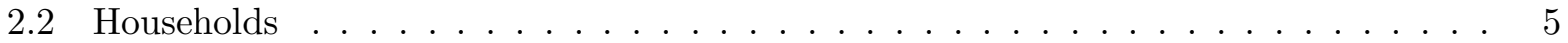

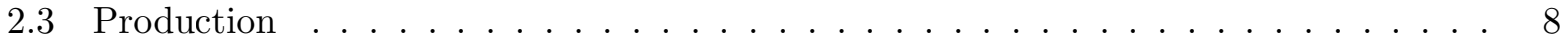

2.3.1 Intermediate Goods Firms . . . . . . . . . . . . . . . . . . 8

2.3 .2 Final Goods Firms . . . . . . . . . . . . . . . . . . . . 8

2.4 Customer Market Matching . . . . . . . . . . . . . . . . . . . . 10

2.5 Price Determination in Customer Markets . . . . . . . . . . . . . . . . . 10

2.6 Government . . . . . . . . . . . . . . . . . . . . . 11

2.7 Private-Sector Equilibrium f . . . . . . . . . . . . . . . . 11

3 Exogenous Policy Estimation $\quad 12$

3.1 Functional Forms and Calibration . . . . . . . . . . . . . . . . . . 12

3.2 Estimation Results . . . . . . . . . . . . . . . . . . . . . . . 13

4 Optimal Policy $\quad 14$

4.1 Ramsey Problem . . . . . . . . . . . . . . . . . . 16

4.2 Computational Issues $\ldots \ldots \ldots \ldots \ldots$

4.3 Results . . . . . . . . . . . . . . . . . . . . 17

4.4 Optimal Policy with Limited Tax Instruments . . . . . . . . . . . . . . . . . . . 19

4.5 Impulse Responses . . . . . . . . . . . . . . . . . . . . . . . . . 21

5 Conclusion $\quad 28$

$\begin{array}{ll}\text { A Related Literature } & 31\end{array}$

B Household Optimization $\quad 33$

B.1 Shopping Conditions . . . . . . . . . . . . . . . . . . . . 34

B.1.1 Credit Shopping Condition . . . . . . . . . . . . . . . . . 34

B.1.2 Cash Shopping Condition . . . . . . . . . . . . . . . . . 35

B.1.3 Envelope Conditions . . . . . . . . . . . . . . . . . . . 37

$\begin{array}{ll}\text { C Firm Optimization } & 38\end{array}$

C.1 Final Goods Firms . . . . . . . . . . . . . . . . . . . . . . . 38

C.1.1 Walrasian Final Goods Firms . . . . . . . . . . . . . . . . . 38 
C.1.2 Customer Market Firms . . . . . . . . . . . . . . . . 38

D Nash-Bargained Prices $\quad 41$

D.1 Value Equations for Household . . . . . . . . . . . . . . . . . . 41

D.1.1 Credit Matches . . . . . . . . . . . . . . . . . . . 41

D.1.2 Cash Matches . . . . . . . . . . . . . . . . . . . . . . 42

D.2 Value Equations for Customer Market Firms . . . . . . . . . . . . . . . . . 42

D.3 Nash Bargaining . . . . . . . . . . . . . . . . . . . . . . . . . . 43

D.3.1 Nash Cash Pricing . . . . . . . . . . . . . . . . . . . . . . . . 44

D.3.2 Nash Credit Pricing . . . . . . . . . . . . . . . . . . 46

$\begin{array}{ll}\text { E Definition of Equilibrium } & 48\end{array}$

F Details of Estimation $\quad 50$

F.1 Computing Steady-State . . . . . . . . . . . . . . . . . . . . . 50

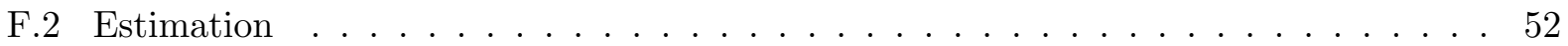

G Ramsey Problem $\quad 54$

H Social Planner $\quad \mathbf{5 6}$

H.1 Static Efficiency - Walrasian "Cash" Good / Walrasian "Credit" Good . . . . . . 56

H.2 Static Efficiency - Consumption-Labor . . . . . . . . . . . . . 57

H.3 Static Efficiency - Consumption-Search . . . . . . . . . . . . . . 57

H.4 Intertemporal Efficiency . . . . . . . . . . . . . . . . . . . . 57

H.5 Efficient Allocations . . . . . . . . . . . . . . . . . . . 58 


\section{Introduction}

Business cycle fluctuations in advertising have gained attention recently, as has the time devoted by households to shopping activities. We describe the behavior of advertising and household time allocation in a natural way, using a customer search and matching framework, in which some markets display sticky nominal price-setting. To capture the cyclical swings in advertising in U.S. data, we first estimate the model, conditional on exogenous fiscal and monetary policy. The estimation reveals that a large departure from efficient pricing in advertising-based markets ("customer markets") is required to capture the empirical advertising volatility along with its strong correlation with GDP. Inefficient customer market pricing is due to congestion externalities that are inherent in matching markets. Given the estimated policy and non-policy parameters, we analyze optimal fiscal and monetary policy in the tradition of Lucas and Stokey (1983), Chari, Christiano, and Kehoe (1991), Schmitt-Grohé and Uribe (2004), and others. A key question is whether optimal policy can restore efficiency in customer search markets as well as mitigate distortions arising through the well-understood sticky-price channel.

Under optimal policy, aggregate business-cycle comovements - for example, GDP, labor, and total consumption - are not much affected by replacement of exogenous policy in the estimated model by endogenous optimal policy. However, Ramsey-optimal volatility in advertising is much smaller than in the data. This result arises because the Ramsey government offsets congestion externalities in customer markets. However, when nominal prices are sticky (as we estimate that they are) monetary policy has little to do with this result; rather, it is fiscal policy that has powerful effects on stabilizing trade in customer markets. An important point that arises from our results is that empirically-observed advertising volatility is inefficiently too high.

Efficient pricing in customer markets is achieved by extreme volatility in several fiscal instruments that are part of a complete system of taxes. Tax rate volatility allows for smoothing the fluctuations of inefficient "wedges" that arise in the estimated exogenous-policy model. However, when prices are sticky, optimal monetary policy does not directly target pricing distortions in customer markets. Instead, consistent with the New Keynesian features of the framework, both optimal inflation volatility and nominal interest rate volatility are extremely small. In contrast, if the New Keynesian aspects are removed, optimal inflation volatility is many magnitudes larger, just as in Chari, Christiano, and Kehoe (1991) and the long line of ensuing research. In fact, optimal inflation volatility under flexible prices is higher in the model with customer markets than in an identically calibrated model without customer search.

The set of taxes that forms the complete set is novel and helps understand the nature of the model, in both positive and normative terms. For example, sales taxes on customer goods help eliminate externalities in customer market pricing, and swing sharply along the business cycle to 
restore intertemporal efficiency in the dynamics of customer relationships. However, several of the taxes in the complete set are difficult to map to governments' policy levers, especially at businesscycle frequencies; because of this, they are not included in the estimation phase. We thus also study a Ramsey government that wields an incomplete set of tax instruments: labor-income taxes, nominal interest rates, and inflation, which are the tax instruments considered in the classical macro-Ramsey models that exclude lump-sum taxes. Wielding this limited set of instruments, labor-income taxes become the primary tool for mitigating price distortions in customer markets, while the role of monetary policy remains, for practical purposes, identical to the model without customer goods.

The recent focus on advertising can be partially attributed to the fact that advertising expenditures are large - they account for 2.5 percent of GDP over the last 50 years, which has been recently documented by, among others, Hall (2013). Using a broader definition of intangible expenses that includes advertising, marketing, and brand promotion, D'Erasmo and Moscoso-Boedo (2013) argue that these expenses can account for up to 13 percent of GDP. Hall (2013) has also characterized advertising volatility as an important component for understanding business cycles. In terms of business-cycle horizons, Molinari and Turino (2009) show that quarterly U.S. volatility in advertising is about three times as volatile as output, highly persistent, and procyclical with respect to output.

To the best of our knowledge, we are the first to estimate such a model using Bayesian methods and consider optimal policy based on the estimates. Our framework brings together several strands of literature. One strand is the money demand macro-Ramsey approach pioneered by Lucas and Stokey (1983) and quantified by Chari, Christiano, and Kehoe (1991). Subsequent authors, including Schmitt-Grohé and Uribe (2004) and Siu (2004), augment these environments with New Keynesian frictions, as we also do here. A second strand considers optimal fiscal policy analysis in models with search and matching in labor markets, a recent example of which is Arseneau and Chugh (2012). A third strand considers the importance of long-lasting customer relationships for the macroeconomy. This literature includes the nascent macro-advertising literature described briefly above. While optimal policy has yet to be considered in these models, both Chahrour and Akinci (2009) and Leith, Moldovan, and Rossi (2012) consider optimal monetary policy in environments where long-term customer relationships are motivated by good-specific (or "deep") habits. Appendix A provides a more detailed review of this third strand of literature and our contribution to it.

The structure of the paper is as follows. Section 2 describes the benchmark exogenous policy model. Section 3 overviews the estimation procedure for the exogenous policy version of the model and compares the fit of the model to the data. Section 4 describes the optimal policy problem with 
a complete set of tax instruments, as well as with an incomplete set of instruments, along with results. Section 5 concludes.

\section{The Economy}

Our model begins with the cash-good/credit-good economy described by Lucas and Stokey (1983), Chari, Christiano, and Kehoe (1991), and summarized in Chari and Kehoe (1999) - hereafter referred to as LS, CCK, and CK, respectively - and layers on top of it the sticky price friction of Rotemberg (1982). The main innovation of our framework relative to this existing literature is to allow for a fraction of goods to require both buyers and sellers to engage in costly search and matching prior to engaging in trade. An important idea in our setup, which does not appear in the recent goods matching and advertising-related macro literature, is that it is realistic that not all goods markets display costly search; this idea is depicted in Figure 1. We allow the Bayesian estimation in Section 3 to determine some important parameters of customer markets. ${ }^{1}$

\subsection{An Overview of Goods Trade in the Model}

Figure 1 sketches the structure of markets; the parts highlighted in red are the components of our model that depart from, say, Siu (2004) and Schmitt-Grohé and Uribe (2004). ${ }^{2}$

A continuum of differentiated firms, indexed by $i$, produce intermediate goods. Each firm $i$ sets its nominal price $p_{i t}$, taking as given its demand function, and incurs convex costs of nominal price adjustment à la Rotemberg (1982). Each firm's technology has identical and exogenous labor productivity $z_{t}$ in each period $t$ and produces $y_{i t}=z_{t} n_{i t}, \forall i \in(0,1)$. These intermediate goods are sold to firms who then costlessly package them into a homogenous final good. The description so far is exactly that of a standard New Keynesian framework.

Where the model differs is that only a fraction of these final goods are exchanged in traditional Walrasian spot markets. For ease of analysis and description, we often refer to final goods producers that sell their goods in the frictionless market as "Walrasian firms." The remaining portion of these goods are sold to consumers through a "customer market" in which relationships must first be established. This channel requires firms to engage in sunk-cost advertising to attract customers. The probability that a given advertisement successfully attracts a potential customer is taken as given by the firm, but is endogenously determined in equilibrium. Hence, the aggregate ratio of

\footnotetext{
${ }^{1}$ The marketing literature has documented how customers decide to establish both long-term relationships with particular firms and anonymous market interactions with others (through spot markets) (Sheth and Shah (2003)).

${ }^{2}$ Schmitt-Grohé and Uribe (2004) do not use a cash-goods/credit-goods framework as Siu (2004) does (they instead use an endogenous transactions velocity framework); however, we will use interchangeably both Siu (2004) and Schmitt-Grohé and Uribe as benchmarks because the results each paper arrives at convey the same ideas.
} 


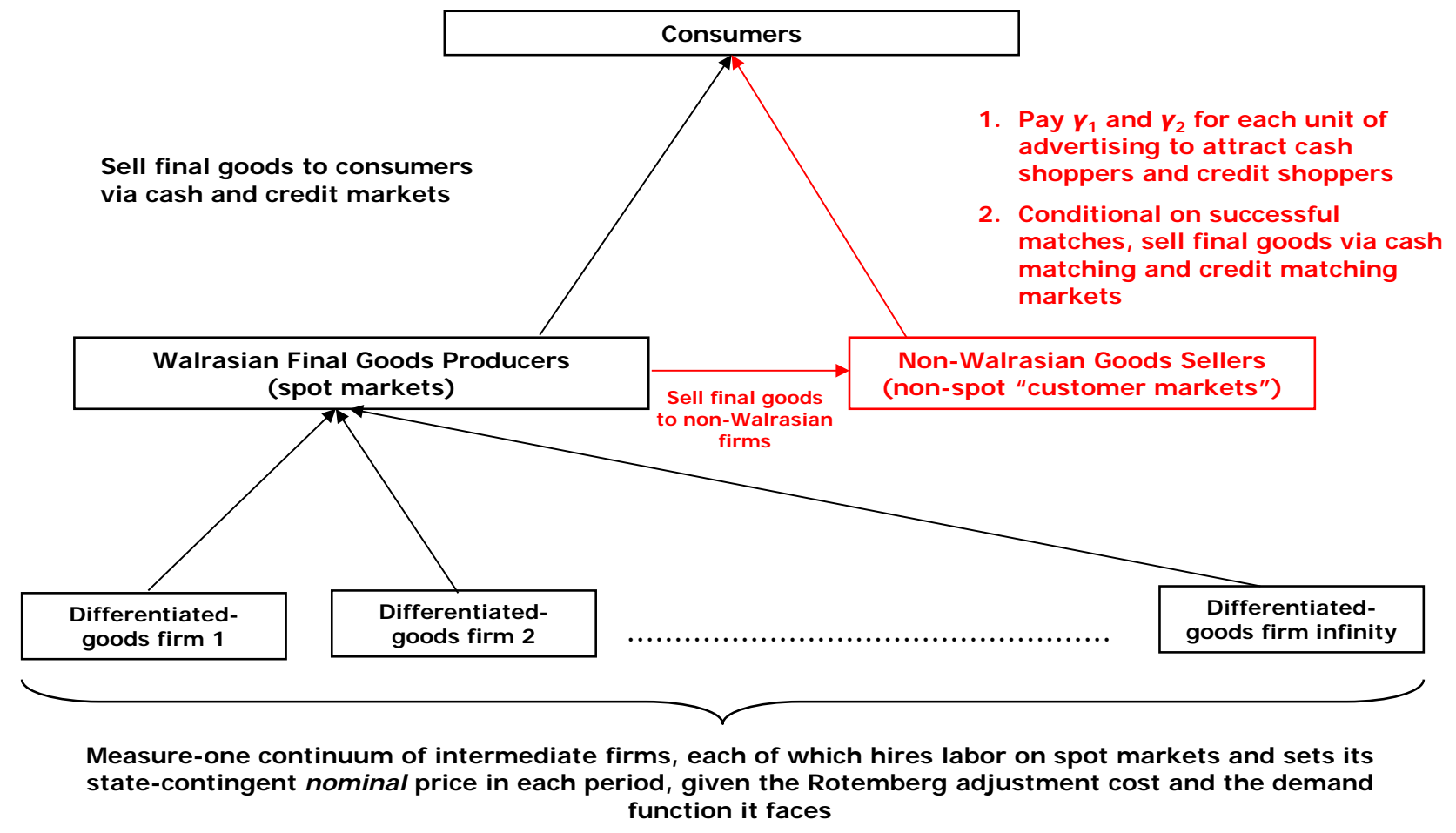

Figure 1: Structure of markets. Differentiated intermediate goods producers hire labor in spot markets and sell their products to Walrasian final goods producers, who in turn costlessly repackage them into final goods. A portion of these goods is sold to consumers, and the remaining portion is sold to non-Walrasian goods sellers. This side of the economy incurs advertising costs to attract customers to whom they sell final goods in non-spot, long-lasting customer relationships. 
advertisers attempting to attract shoppers to the number of shoppers trying to form new customer matches (termed "market tightness" in the well-known labor search and matching literature) is critical for these matching rates, and hence for customer goods' prices. Congestion externalities occur because traders on either side of the market do not take into account their effect on aggregate matching probabilities. Generically, congestion externalities exist in matching markets.

Conditional on successfully attracting a customer, a customer relationship is established. Once established, the customer relationship persists until it ends in an exogenous separation, which occurs with a constant probability each period. In order to facilitate comparison with the benchmark optimal policy models of LS and CCK, our model allows for both cash and credit transactions in both Walrasian markets and customer markets.

\subsection{Households}

There is a measure one of identical, infinitely-lived households in the economy, each composed of a measure one of individuals. In a given period, an individual member of the representative household can be engaged in one of four activities: searching for cash goods, searching for credit goods, working, or enjoying leisure. More specifically, $l_{t}$ members of the household are working in a given period; $s_{1 t}\left(s_{2 t}\right)$ members are searching for customer market firms with which to establish cash (credit) relationships; and $1-l_{t}-s_{1 t}-s_{2 t}$ members are enjoying leisure. Let $x_{1 t}$ and $x_{2 t}$ stand for Walrasian cash-good consumption and credit-good consumption, respectively.

Denote by $N_{1 t}$ and $N_{2 t}$ the pre-existing stocks of customer cash-good relationships and customer credit-good relationships, respectively. In each relationship, one unit of consumption is traded. In other words, there is no intensive margin of trade. All goods exchange in customer markets occurs at the extensive level.

The representative household maximizes expected lifetime utility

$$
\max E_{0} \sum_{t=0}^{\infty} \beta^{t}\left[u\left(x_{1 t}, x_{2 t}\right)+\vartheta v\left(N_{1 t}, N_{2 t}\right)-h\left(l_{t}+s_{1 t}+s_{2 t}\right)\right]
$$

subject to the sequence of flow budget constraints (which contain several taxes, which are part of the complete set of tax instruments analyzed in the Ramsey problem)

$$
\begin{aligned}
M_{t}-M_{t-1}+B_{t}-R_{t-1} B_{t-1}= & \left(1-\tau_{t-1}^{l}\right) P_{t-1} w_{t-1} l_{t-1}-P_{t-1} x_{1 t-1} \\
& -P_{t-1} x_{2 t-1}-P_{1 t-1}\left(1+\tau_{t-1}^{N_{1}}\right) N_{1 t-1} \\
& -P_{2 t-1}\left(1+\tau_{t-1}^{N_{2}}\right) N_{2 t-1}+\left(1-\tau^{d}\right) d_{t-1}+\left(1-\tau^{d^{N K}}\right) d_{t-1}^{N K} \\
& +\left[\left(1-k_{1 t-1}^{h}\right) s_{1 t-1}+\left(1-k_{2 t-1}^{h}\right) s_{2 t-1}\right] P_{t-1} \kappa,
\end{aligned}
$$

cash-in-advance constraints

$$
P_{t} x_{1 t}+P_{1 t}\left(1+\tau_{t}^{N_{1}}\right) N_{1 t} \leq M_{t}
$$


and perceived laws of motion for its cash customer relationships and credit customer relationships

$$
N_{1 t+1}=(1-\rho)\left(N_{1 t}+s_{1 t} k_{1 t}^{h}\right)
$$

and

$$
N_{2 t+1}=(1-\rho)\left(N_{2 t}+s_{2 t} k_{2 t}^{h}\right)
$$

in which $\rho$ is the customer turnover rate. The within-period timing of financial markets relative to allocation markets is identical to that in LS and CCK, and we have introduced customer markets in a symmetric fashion. The importance of customer goods in households' preferences is captured by the utility parameter $\vartheta$ in (1). As $\vartheta$ shrinks to zero, the model nests that of LS, CCK, Siu (2004), and (effectively) Schmitt-Grohé and Uribe (2004). To capture the idea that some fraction of customer consumption requires a cash-in-advance constraint, we include $N_{1 t}$ in (3).

The perceived probabilities, which are taken as given by individuals searching for new cash (credit) customer market relationships, are $k_{1 t}^{h}\left(k_{2 t}^{h}\right){ }^{3}$ Purchases of customer market goods are taxed at the rates $\tau_{t}^{N_{1}}$ and $\tau_{t}^{N_{2}}$, and pre-tax labor income $w_{t} l_{t}$ is taxed at the rate $\tau_{t}^{l}$. Each unmatched shopper, whether a cash shopper or a credit shopper, receives a "coupon" $\kappa$ from the government. ${ }^{4} P_{t}$ denotes the period- $t$ nominal price of any Walrasian good (cash or credit), $P_{1 t}$ denotes the period- $t$ nominal price of a cash customer good, and $P_{2 t}$ denotes the period- $t$ nominal price of a credit customer good. Aggregate profits of the differentiated goods sector are rebated as lump-sum dividends $d_{t-1}^{N K}$ to the representative household every period, as are aggregate profits of the customer market firms $d_{t-1}$. Because of their lump-sum nature, the optimal tax rate $\tau^{d^{N K}}$ imposed by the Ramsey planner would be 100 percent (as shown by Schmitt-Grohé and Uribe (2004) and Siu (2004)), and the optimal $\tau^{d}$ imposed by the Ramsey planner would also be 100 percent (as shown by Arseneau and Chugh (2012)). ${ }^{5}$

First-order conditions with respect to $x_{1 t}, x_{2 t} l_{t}, s_{1 t}, s_{2 t}, N_{1 t+1}, N_{2 t+1}, M_{t}$, and $B_{t}$ yield (details are provided in Appendix B) a standard (Walrasian credit) consumption-labor optimality condition

$$
\frac{h^{\prime}\left(l_{t}+s_{1 t}+s_{2 t}\right)}{u_{x_{2 t}}}=\left(1-\tau_{t}^{l}\right) w_{t}
$$

a standard (Walrasian) cash-good/credit-good optimality condition

$$
\frac{u_{x_{1 t}}}{u_{x_{2 t}}}=R_{t}
$$

\footnotetext{
${ }^{3}$ These perceived probabilities will be determined in general equilibrium.

${ }^{4}$ The coupon $\kappa$ could be interpreted in different ways. In this paper, we interpret them as government-provided income.

${ }^{5}$ For the Ramsey analysis, these 100 percent tax rates are presumed to not generate sufficient revenue to finance exogenous total government spending.
} 
and the pricing condition for the one-period nominally risk-free government bond

$$
1=R_{t} E_{t}\left[\frac{\beta u_{x_{1 t+1}}}{u_{x_{1 t}}} \frac{1}{\pi_{t+1}}\right]
$$

in which $\pi_{t} \equiv P_{t} / P_{t-1}$ is the gross inflation rate between periods $t-1$ and $t{ }^{6}$

The two other household optimality conditions that arise are the cash-shopping condition

$$
\begin{aligned}
& \frac{h_{t}^{\prime}}{u_{x_{2 t}}} \frac{1}{k_{1 t}^{h}}-\left(\frac{1-k_{1 t}^{h}}{k_{1 t}^{h}}\right) \kappa= \\
& \quad+(1-\rho) E_{t}\left\{\Xi_{t+1 \mid t}\left[\frac{\vartheta v_{N_{1 t+1}}}{u_{x_{2 t+1}}}-p_{1 t+1} R_{t+1}\left(1+\tau_{t+1}^{N_{1}}\right)+\frac{h_{t+1}^{\prime}}{u_{x_{2 t+1}}} \frac{1}{k_{1 t+1}^{h}}-\left(\frac{1-k_{1 t+1}^{h}}{k_{1 t+1}^{h}}\right) \kappa\right]\right\} .
\end{aligned}
$$

and the credit-shopping condition

$$
\begin{aligned}
& \frac{h_{t}^{\prime}}{u_{x_{2 t}}} \frac{1}{k_{2 t}^{h}}-\left(\frac{\left.1-k_{2 t}^{h}\right)}{k_{2 t}^{h}}\right) \kappa= \\
& \quad=(1-\rho) E_{t}\left\{\Xi_{t+1 \mid t}\left[\frac{\vartheta v_{N_{2 t+1}}}{u_{x_{2 t+1}}}-\left(1+\tau_{t+1}^{N_{2}}\right) p_{2 t+1}+\frac{h_{t+1}^{\prime}}{u_{x_{2 t+1}}} \frac{1}{k_{2 t+1}^{h}}-\left(\frac{1-k_{2 t+1}^{h}}{k_{2 t+1}^{h}}\right) \kappa\right]\right\} .
\end{aligned}
$$

Each shopping condition equates the marginal cost of sending a member of the household to search for either a new cash or a new credit customer market relationship to its expected payoff. Taking the credit shopping condition (10) as an example, the cost is the marginal rate of substitution (MRS) $\frac{h_{t}^{\prime}}{u_{x_{2} t}}$. The expected payoff contains two parts. If the credit shopper is unsuccessful in finding a customer market firm, which occurs with probability $1-k_{2 t}^{h}$, the individual (and thus the household of which he is a member) receives the coupon payoff $\kappa$. On the other hand, if the shopper is successful, which occurs with probability $k_{2 t}^{h}$, the individual (and thus the household of which he is a member) receives the payoff stated in the second line of (10). This latter payoff (which begins in period $t+1$, due to the assumed timing of customer markets), is the MRS between search credit goods and Walrasian credit goods, $\frac{\vartheta v_{N_{2 t+1}}}{u_{x_{2 t+1}}}$, net of the consumer's after-tax payment. Because customer market relationships are long-lived, a continuation value also appears in this payoff. The interpretation of the cash shopping condition (9) is similar, except, because these are cash goods, the nominal interest rate also appears in the after-tax payment.

\footnotetext{
${ }^{6}$ For ease of notation, sometimes we drop the arguments of marginal utility functions. For example, $h^{\prime}\left(l_{t}+s_{1 t}+\right.$ $\left.s_{2 t}\right)=h_{t}^{\prime}$.
} 


\subsection{Production}

\subsubsection{Intermediate Goods Firms}

As shown in Figure 1, imperfectly substitutable intermediate goods are produced by a continuum of firms indexed by $i$, using labor as the only input into production. These intermediate inputs are then sold to final goods producers. Each intermediate goods firm $i$ sets its nominal price, $p_{i, t}$, to maximize monopoly profits subject to the following demand curve for its differentiated intermediate input

$$
y_{i, t}=\left(\frac{p_{i, t}}{P_{t}}\right)^{-\varepsilon} y_{t}
$$

in which the elasticity of the demand for firm $i$ 's intermediate input is $\frac{\varepsilon-1}{\varepsilon}$ and aggregate demand is denoted $y_{t}$. Each firm $i$ produces using a linear-in-labor technology, $y_{i, t}=z_{t} l_{i t}$, taking as given the nominal wage $W_{t}$, and $z_{t}$ stands for aggregate labor productivity, which we will interchangeably refer to as total factor productivity (TFP). TFP is assumed to be common across all intermediate goods producing firms.

For firm $i$ 's profit maximization problem, define the aggregate real wage, $w_{t} \equiv \frac{W_{t}}{P_{t}}$, aggregate marginal cost, $m c_{t}=\frac{w_{t}}{z_{t}}$, and aggregate gross inflation, $\pi_{t}=\frac{P_{t}}{P_{t-1}}$. Each firm $i$ pays a cost,

denominated in aggregate output, of $\frac{\varphi}{2}\left(\frac{p_{i, t}}{p_{i, t-1}}-\pi_{i}\right)^{2}$ for adjusting prices. Letting $\Xi_{t \mid 0}$ denote the $t$-period ahead stochastic discount factor of households, firm $i$ 's problem is

$$
\max _{p_{i, t}, y_{i, t}} E_{0} \sum_{t=0}^{\infty} \frac{\Xi_{t \mid 0}}{P_{t}}\left[p_{i, t} y_{i, t}-P_{t} m c_{t} y_{i t}-\frac{\varphi}{2}\left(\frac{p_{i, t}}{p_{i, t-1}}-\pi^{*}\right)^{2} P_{t}\right]
$$

subject to its demand constraint (11).

Taking the two first order conditions and imposing symmetric equilibrium $\left(p_{i, t}=P_{t}\right.$ and $y_{i, t}=$ $\left.y_{t}, \forall i\right)$ yields the well-known New Keynesian Phillips Curve (NKPC),

$$
0=\left(1-\varepsilon+\varepsilon m c_{t}\right) y_{t}-\varphi\left(\pi_{t}-\pi^{*}\right) \pi_{t}+E_{t}\left\{\Xi_{t+1 \mid t} \varphi\left(\pi_{t+1}-\pi^{*}\right) \pi_{t+1}\right\} .
$$

For the Ramsey problem below, symmetric equilibrium real profits (which are the dividends that the consumers receive lump-sum in (2)) of the representative intermediate goods producer in period $t$ are given by

$$
d_{t}^{N K}=\left(1-m c_{t}\right) y_{t}-\frac{\varphi}{2}\left(\pi_{t}-\pi^{*}\right)^{2}
$$

\subsubsection{Final Goods Firms}

Again referring to Figure 1, final goods can be sold to households either through a Walrasian market - meaning the goods are sold directly to consumers in a Walrasian market — or through a customer market. Customer market sales are conducted in non-Walrasian search and matching markets that require advertising on the part of customer marketers to attract searching consumers. 
Regardless of which market the goods are purchased in, final goods are produced via DixitStiglitz bundling of intermediate goods. The price elasticity of demand for each of the intermediate goods is $\varepsilon$, and thus the elasticity of demand across intermediate producers will be $\frac{\varepsilon-1}{\varepsilon}$.

Walrasian Market. Firms in Walrasian markets are perfectly competitive, so we can simply describe the representative Walrasian firm. The representative Walrasian firm produces final goods according to the CES production function $X_{j, t}=\left(\int x_{i, t}^{\frac{\frac{\varepsilon-1}{\varepsilon}}{\varepsilon}} d i\right)^{\frac{\varepsilon}{\varepsilon-1}}$, in which $x_{i, t}$ represents units of intermediate good $i$ used in the production of Walrasian goods. ${ }^{7}$ Optimization with respect to $x_{i, t}$ yields the demand function in (11).

Walrasian goods are sold in perfectly competitive markets to both households and customer marketers. The nominal price of the Walrasian goods is $P_{t}$. If all goods are sold in the Walrasian market, which occurs if the utility weight on customer market goods in the household's utility function is $\vartheta=0$, the model is simply that of Schmitt-Grohé and Uribe (2004) and Siu (2004).

Customer Market. Firms in customer markets all face the same costs of advertising and all sell the same physical object as Walrasian firms, thus we can simply describe the representative customer market firm. Similar to the representative household, the representative customer market firm has $N_{1 t}$ and $N_{2 t}$ pre-existing stocks of customer market cash-good relationships and customer market credit-good relationships. The representative customer marketer maximizes

$$
\max _{N_{1 t+1}, N_{2 t+1}, a_{1 t}, a_{2 t}} E_{0} \sum_{t=0}^{\infty} \Xi_{t \mid 0}\left[\left(p_{1 t}-1\right) N_{1 t}+\left(p_{2 t}-1\right) N_{2 t}-\left(1-\tau_{t}^{a_{1}}\right) \gamma_{1} a_{1 t}-\left(1-\tau_{t}^{a_{2}}\right) \gamma_{2} a_{2 t}\right]
$$

subject to perceived laws of motion

$$
N_{1 t+1}=(1-\rho)\left(N_{1 t}+k_{1 t}^{f} a_{1 t}\right)
$$

and

$$
N_{2 t+1}=(1-\rho)\left(N_{2 t}+k_{2 t}^{f} a_{2 t}\right) .
$$

The relative price for a search cash (credit) good is $p_{1 t} \equiv P_{1 t} / P_{t}\left(p_{2 t} \equiv P_{2 t} / P_{t}\right), k_{1 t}^{f}\left(k_{2 t}^{f}\right)$ is the probability of a given advertisement yielding a cash (credit) match, $a_{1 t}\left(a_{2 t}\right)$ is advertising to attract cash (credit) matches, $\gamma_{1}\left(\gamma_{2}\right)$ parameterizes the cost of cash (credit) advertising, and $\tau^{a_{1}}\left(\tau^{a_{2}}\right)$ is a government subsidy for costly cash (credit) advertising.

The first-order conditions with respect to $a_{1 t}$ and $N_{1 t+1}$ and, similarly, $a_{2 t}$ and $N_{2 t+1}$, yield a pair of optimal advertising conditions that characterize customer marketers' investments in attracting new customers. These optimal advertising conditions are given by

$$
\frac{\left(1-\tau_{t}^{a_{1}}\right) \gamma_{1}}{k_{1 t}^{f}}=(1-\rho) E_{t}\left\{\Xi_{t+1 \mid t}\left(p_{1 t+1}-1+\frac{\left(1-\tau_{t+1}^{a_{1}}\right) \gamma_{1}}{k_{1 t+1}^{f}}\right)\right\},
$$

\footnotetext{
${ }^{7}$ Note that $x, p$, and $X$ are chosen to describe the firm-level problems in this section only. Thus, for example, $p_{j, t}$ denotes the nominal price chosen by final goods producer $j$; it does not denote the Nash-bargained prices $p_{1 t}$ or $p_{2 t}$ characterized in Section 2.5 below.
} 
for cash matches and

$$
\frac{\left(1-\tau_{t}^{a_{2}}\right) \gamma_{2}}{k_{2 t}^{f}}=(1-\rho) E_{t}\left\{\Xi_{t+1 \mid t}\left(p_{2 t+1}-1+\frac{\left(1-\tau_{t+1}^{a_{2}}\right) \gamma_{2}}{k_{2 t+1}^{f}}\right)\right\} .
$$

for credit matches.

Intuitively, customer-market firms advertise to the point at which the marginal cost of advertising and successfully forming a new customer relationship (the left-hand side of (18) and (19)) equates with the present value of profits (the right-hand side of (18) and (19)).

\subsection{Customer Market Matching}

In aggregate, matches between cash (credit) shoppers looking for customer market firms and customer marketers' cash (credit) advertising are formed according to a pair of constant-returns matching technologies, and $s_{1 t}\left(s_{2 t}\right)$ and $a_{1 t}\left(a_{2 t}\right)$ are now considered to be economywide aggregates. The aggregate law of motion for cash customer relationships is

$$
N_{1 t+1}=(1-\rho)\left(N_{1 t}+m\left(s_{1 t}, a_{1 t}\right)\right)
$$

and the aggregate law of motion for credit customer relationships is

$$
N_{2 t+1}=(1-\rho)\left(N_{2 t}+m\left(s_{2 t}, a_{2 t}\right)\right) .
$$

The aggregate matching function is $m(s, a)$. In the estimation in Section 3 and therefore in the Ramsey problem in Section 4, the matching functions are identical regardless of customer market cash or customer market credit, but the inputs $s$ and $a$ can differ.

\subsection{Price Determination in Customer Markets}

Successful matches generate surpluses that reflect the value of customer relationship capital generated as a result of the costly search process. The price of these goods - the terms of goods trade - splits this surplus between both sides of each relationship market.

As is typical in the search and matching literature, we assume this price is determined as the outcome of a generalized individualistic Nash bargaining process. Specifically, once a match is formed, both consumers and customer marketers sit down to bargain and ultimately settle on a price that maximizes the surplus of the match conditional on the bargaining power of customers, $\eta_{i}$, and customer marketers, $1-\eta_{i}$ for market $i \in(1,2)$ and for $\eta_{i} \in(0,1)$. Details of the derivation are provided in Appendix D; due to space considerations, we present here only the Nash pricing condition for cash customer goods

$$
p_{1 t}=\left(1-\eta_{1}\right)\left(\frac{\vartheta v_{N_{1}}\left(N_{1 t}, N_{2 t}\right) / u_{x_{2}}\left(x_{1 t}, x_{2 t}\right)-\kappa}{R_{t}\left(1+\tau_{t}^{N_{1}}\right)}\right)+\eta_{1}
$$




$$
+\eta_{1}(1-\rho) E_{t}\left\{\Xi_{t+1 \mid t}\left[\frac{R_{t+1}\left(1+\tau_{t+1}^{N_{1}}\right)}{R_{t}\left(1+\tau_{t}^{N_{1}}\right)}-1\right] \mathbf{A}_{1 t+1}\right\}
$$

in which $\mathbf{A}_{1 t+1}$ denotes the present value to a firm of a cash customer market customer, and the Nash pricing condition for credit customer goods

$$
\begin{aligned}
p_{2 t} & =\left(1-\eta_{2}\right)\left(\frac{\vartheta v_{N_{2}}\left(N_{1 t}, N_{2 t}\right) / u_{x_{2}}\left(x_{1 t}, x_{2 t}\right)-\kappa}{1+\tau_{t}^{N_{2}}}\right)+\eta_{2} \\
& +\eta_{2}(1-\rho) E_{t}\left\{\Xi_{t+1 \mid t}\left[\frac{1+\tau_{t+1}^{N_{2}}}{1+\tau_{t}^{N_{2}}}-1\right] \mathbf{A}_{2 t+1}\right\},
\end{aligned}
$$

in which, similarly, $\mathbf{A}_{2 t+1}$ denotes the present value to a firm of a credit customer market customer. We allow for a customer's bargaining power $\left(\eta_{1}\right.$ vs. $\left.\eta_{2}\right)$ to potentially differ across the search-based cash and credit goods for estimation purposes, as discussed in Section 3. It is also useful to note that there are a variety of policy tools — indeed, they are part of the complete set of tax instruments that can potentially affect prices in relationship markets. The ability of an optimizing government to use these tax instruments to alter the way the surpluses are split is critical for the Ramsey problem studied in Section 4.

\subsection{Government}

The government's flow budget constraint in nominal terms is

$$
\begin{aligned}
M_{t}+ & B_{t}+\tau_{t-1}^{l} P_{t-1} w_{t-1} l_{t-1}+P_{1 t-1} \tau_{t-1}^{N 1} N_{1 t-1}+P_{2 t-1} \tau_{t-1}^{N 2} N_{2 t-1}+\tau^{d} P_{t-1} d_{t-1}+\tau^{N K} P_{t-1} d_{t-1}^{N K} \\
= & M_{t-1}+R_{t-1} B_{t-1}+P_{t-1} g_{t-1}+\left[\left(1-k_{1 t-1}^{h}\right) s_{1 t-1}+\left(1-k_{2 t-1}^{h}\right) s_{2 t-1}\right] P_{t-1} \kappa \\
& +P_{t-1} \tau_{t-1}^{a 1} \gamma_{1} a_{1 t-1}+P_{t-1} \tau_{t-1}^{a 2} \gamma_{2} a_{2 t-1}+P_{t-1}\left(1-\tau_{t-1}^{l}\right) w_{t-1} l_{t-1},
\end{aligned}
$$

where $g_{t}$ denotes exogenous government expenditure in period $t$.

\subsection{Private-Sector Equilibrium}

Taking as given the exogenous processes $\left\{z_{t}, g_{t}, \tau_{t}^{l}, \mu_{t}, \tau_{t}^{N_{1}}, \tau_{t}^{N_{2}}, \tau_{t}^{a_{1}}, \tau_{t}^{a_{2}}\right\}^{8}$, the decentralized search equilibrium is a set of state-contingent functions for $\left\{x_{1 t}, x_{2 t}, l_{t}, a_{1 t}, s_{1 t}, a_{2 t}, s_{2 t}, N_{1 t+1}, N_{2 t+1}, w_{t}\right.$, $\left.m c_{t}, p_{1 t}, p_{2 t}, R_{t}, \pi_{t}, \mathbf{A}_{1 t}, \mathbf{A}_{2 t},\right\}$ that satisfy: the consumption-leisure optimality condition (6); the Walrasian cash goods/credit goods optimality condition (7); the nominal bond Euler equation (8); the cash shopping condition (9); the credit shopping condition (10); the New Keynesian Phillips Curve (13); the cash advertising condition (18); the credit advertising condition (19); the aggregate

\footnotetext{
${ }^{8}$ Following much of the related literature, in all of our results we have also assumed a fixed subsidy $\tau^{w}$ which offsets the steady-state markup created by imperfect competition in the model. None of our results depend on this assumption.
} 
law of motion for cash relationships (20) and credit relationships (21); the Nash pricing conditions (22) and (23); the government budget constraint (24); the binding CIA constraint (stated in real terms)

$$
\frac{x_{1 t}+\left(1+\tau_{t}^{N_{1}}\right) p_{1 t} N_{1 t}}{x_{1 t-1}+\left(1+\tau_{t-1}^{N_{1}}\right) p_{1 t-1} N_{1 t-1}}=\frac{\mu_{t}}{\pi_{t}}
$$

the definitions of the present-value to a firm, respectively, of a cash customer market relationship

$$
\mathbf{A}_{1 t}=p_{1 t}-1+(1-\rho) E_{t}\left\{\Xi_{t+1 \mid t}\left[p_{1 t+1}-1+\frac{\left(1-\tau_{t+1}^{a_{1}}\right) \gamma_{1}}{k_{1 t+1}^{f}}\right]\right\}
$$

and a credit customer market relationship

$$
\mathbf{A}_{2 t}=p_{2 t}-1+(1-\rho) E_{t}\left\{\Xi_{t+1 \mid t}\left[p_{2 t+1}-1+\frac{\left(1-\tau_{t+1}^{a_{2}}\right) \gamma_{2}}{k_{2 t+1}^{f}}\right]\right\}
$$

and the aggregate goods resource constraint

$$
x_{1 t-1}+x_{2 t-1}+N_{1 t-1}+N_{2 t-1}+g_{t-1}+\gamma_{1} a_{1 t-1}+\gamma_{2} a_{2 t-1}+\frac{\varphi}{2}\left(\pi_{t-1}-\pi^{*}\right)=z_{t-1} l_{t-1}
$$

The resource constraint is stated in period $t-1$ terms because of the timing of markets in the model — specifically, because (all) goods are paid for with a one period lag, summing the time- $t$ consumer and government budget constraints gives rise to the time- $(t-1)$ goods resource constraint. ${ }^{9}$

\section{Exogenous Policy Estimation}

\subsection{Functional Forms and Calibration}

The instantaneous utility over Walrasian cash and credit goods is

$$
u\left(x_{1 t}, x_{2 t}\right)=\frac{\left\{\left[\left(1-\kappa_{x}\right) x_{1 t}^{\phi_{x}}+\kappa_{x} x_{2 t}^{\phi_{x}}\right]^{\frac{1}{\phi_{x}}}\right\}^{1-\sigma_{x}}-1}{1-\sigma_{x}}
$$

This CES aggregate of cash and credit goods nested inside CRRA utility is standard in cash/credit goods models. We assume a symmetric utility function over non-Walrasian cash and credit goods,

$$
v\left(N_{1 t}, N_{2 t}\right)=\frac{\left\{\left[\left(1-\kappa_{c}\right) N_{1 t}^{\phi_{c}}+\kappa_{c} N_{2 t}^{\phi_{c}}\right]^{\frac{1}{\phi_{c}}}\right\}^{1-\sigma_{c}}-1}{1-\sigma_{c}} .
$$

Instantaneous utility over leisure is given by

$$
h\left(l_{t}+s_{1 t}+s_{2 t}\right)=\frac{\zeta}{1+\frac{1}{\nu}}\left(s_{1 t}+s_{2 t}+l_{t}\right)^{1+\frac{1}{\nu}} .
$$

\footnotetext{
${ }^{9}$ This specification is exactly the same as in Lucas and Stokey (1983) and Chari and Kehoe (1999). We note a technical issue this timing imposes on the formulation of the Ramsey problem below.
} 
We use standard functional forms to search in matching in the economy. The matching function is Cobb-Douglas,

$$
m_{i}\left(s_{i}, a_{i}\right)=\psi_{i} s_{i}^{\xi_{s}} a_{i}^{1-\xi_{s}}, \quad i=1,2
$$

Define market tightness in market $i$ as $\theta_{i}=\frac{a_{i}}{s_{i}}$. Then

$$
k_{i}^{h}=\frac{m_{i}\left(s_{i}, a_{i}\right)}{s_{i}}=m_{i}\left(1, \theta_{i}\right)=\theta_{i} k_{i}^{f}
$$

\section{$3.2 \quad$ Estimation Results}

Given the above equilibrium conditions, we proceed to estimate the model using Bayesian methods. We assume that technology, government and spending follow exogenous AR(1) processes in logs:

$$
\begin{aligned}
\log z_{t} & =\rho_{z} \log z_{t-1}+\epsilon_{t}^{z} \\
\log \left(g_{t} / \bar{g}\right) & =\rho_{g} \log \left(g_{t-1} / \bar{g}\right)+\epsilon_{t}^{g} \\
\log \left(\tau_{t}^{l} / \bar{\tau}^{l}\right) & =\rho_{\tau^{l}} \log \left(\tau_{t-1}^{l} / \bar{\tau}^{l}\right)+\epsilon_{t}^{\tau^{l}}
\end{aligned}
$$

In our empirical implementation of the model, we also assume that the remaining taxes $\tau_{t}^{N_{1}}=$ $\tau_{t}^{N_{2}}=\tau_{t}^{a_{1}}=\tau_{t}^{a_{2}}=\tau_{t}^{w}=0$ for all $t$.

Given the emphasis of contemporary monetary policy on the nominal interest rate, we further assume that $R_{t}$ is specified according to a Taylor-type rule with interest rate smoothing, and that money growth, $\mu_{t}$, adjusts endogenously to implement that rate. Deviations from the Taylor rule are captured by i.i.d. monetary shocks, $\epsilon_{t}^{R}$. Specifically,

$$
\log \left(R_{t} / R\right)=\rho_{r} \log \left(R_{t-1} / R\right)+\left(1-\rho_{r}\right)\left[\alpha_{\pi} \log \left(\pi_{t} / \pi^{*}\right)+\alpha_{y} \log \left(y_{t} / \bar{y}\right)\right]+\epsilon_{t}^{R}
$$

The innovations $\epsilon_{t}^{j}, j=z, g, \tau^{l}, R$ are distributed $N\left(0, \sigma_{\epsilon_{t}^{j}}^{2}\right)$ and are independent of each other. For the estimation, we use data on $Y_{t}=\left[\Delta G D P_{t}, \pi_{t}, R_{t}, \Delta A_{t}^{\text {annual }}\right]$. The data are described in the appendix. Since we have only annual data for advertising, we use an unbalanced panel, and a version of the Kalman filter that accounts for missing observations.

Table 1 describes how well the estimated model fits with the dimensions of the data used for estimation. Qualitatively, the model does a very good job at matching the unconditional moments of the data. Volatilities and cross-correlations of the data are very closely matched. One exception is the autocorrelation of output growth, which is lower in the model than in the data, perhaps reflecting the fact that our priors do allow for the possibility of a random walk on the exogenous processes.

Table 2 summarizes the prior and posterior distributions for the estimated parameters. Our estimate of price stickiness is largely in line with previous estimates and calibrations. The intertemporal elasticity of substitution parameter $\sigma_{c}=\sigma_{x}$ is estimated to be substantially greater 


\begin{tabular}{llll}
\hline \hline$\Delta y$ & $\Delta a^{\text {annual }}$ & $\pi$ & $R$ \\
\hline
\end{tabular}

Data

$\begin{array}{lrrrr}\text { Abs. volatility } & 0.86 & 4.44 & 0.55 & 0.69 \\ \text { Autocorr. } & 0.33 & 0.18 & 0.87 & 0.96 \\ \text { Corr. with GDP } & 1 & 0.23 & -0.29 & -0.13\end{array}$

$\underline{\text { Model }}$

\begin{tabular}{lrrrr} 
Abs. volatility & 0.97 & 5.21 & 0.47 & 0.62 \\
Autocorr. & 0.04 & 0.06 & 0.76 & 0.91 \\
Corr. with GDP & 1 & 0.16 & -0.10 & -0.04 \\
\hline
\end{tabular}

Table 1: Data vs. Model. Upper panel displays the empirical growth rate of GDP, annual growth rate of advertising, inflation, and three-month interest rate. Bottom panel displays estimated model analogs.

than unity. The estimates for the parameters driving the exogenous processes are not surprising, although the data imply that technology shocks are extremely persistent and account for a large portion of the variance of output in the economy at longer frequencies.

The two estimated parameters that bear most on optimal policy are the Nash bargaining parameters and the value of the outside option $\kappa$. These two parameters govern congestion externalities in customer markets. Just as in labor search and matching models, if these externalities do not cancel out, prices and hence allocations are inefficient. ${ }^{10}$ While most parameters are well identified and very precisely estimated, the confidence bounds on the Nash bargaining parameters are somewhat large. However, the large value of $\kappa$ is precisely estimated and substantially larger than our priors. Because $\kappa$ is not a primitive of the economy (it appears in neither household utility nor the resource constraint), the estimated $\kappa=0.59$ indicates a strong inefficiency in customer market pricing.

\section{Optimal Policy}

For the sake of comparison with the Ramsey optimal policy results, Table 3 presents standard business-cycle comovements in the estimated model using both TFP shocks and government spend-

\footnotetext{
${ }^{10}$ This intuition follows from the well-known analysis of Hagedorn and Manovskii (2008) in labor-matching models.
} 


\begin{tabular}{|l|l|ll|}
\hline & Median & $\mathbf{5 \%}$ & $\mathbf{9 5 \%}$ \\
\hline$\varphi$ & 18.85 & 12.44 & 25.77 \\
$\rho$ & 0.50 & 0.49 & 0.51 \\
$\kappa$ & 0.59 & 0.40 & 0.72 \\
$\eta_{1}$ & 0.43 & 0.27 & 0.63 \\
$\eta_{2}$ & 0.46 & 0.29 & 0.66 \\
$\sigma_{x}=\sigma_{c}$ & 2.72 & 2.34 & 3.14 \\
$\sigma_{r}$ & 0.00 & 0.00 & 0.00 \\
$\sigma_{z}$ & 0.01 & 0.01 & 0.02 \\
$\sigma_{g}$ & 0.04 & 0.04 & 0.05 \\
$\sigma_{\tau}$ & 0.08 & 0.06 & 0.10 \\
$\rho_{r}$ & 0.76 & 0.73 & 0.80 \\
$\rho_{z}$ & 0.99 & 0.98 & 0.99 \\
$\rho_{g}$ & 0.93 & 0.91 & 0.95 \\
$\rho_{\tau}$ & 0.81 & 0.76 & 0.85 \\
$\alpha_{\pi}$ & 1.68 & 1.47 & 1.96 \\
$\alpha_{y}$ & 0.01 & 0.00 & 0.02 \\
\hline
\end{tabular}

Table 2: Estimated Parameters. 
ing shocks. In all subsequent tables, we compute the model moments based on many 100-period simulations in which the realizations of the exogenous shocks hitting the economy are the same for each table row. This ensures that any differences are due to differences in the economy and not sampling errors.

With the baseline calibration established, we now discard the exogenous process (36) for the labor income tax rate and the Taylor rule (37) and instead endogenize both income and customer good tax policy. ${ }^{11}$ While taxes are now optimally chosen by a Ramsey government, government purchases continue to follow the exogenous process (35), as does the exogenous productivity process (34). ${ }^{12}$ Given the complexity of the model, we use the dual approach for the Ramsey analysis, in which (as defined immediately below) all allocations and policy instruments are chosen subject to all of the market equilibrium conditions.

\subsection{Ramsey Problem}

The Ramsey problem is to choose state-contingent processes $\left\{x_{1 t}, x_{2 t}, l_{t}, N_{1 t+1}, N_{2 t+1}, s_{1 t}, s_{2 t}, \theta_{1 t}, \theta_{2 t}, m c_{t}, p_{1 t}, p_{2 t}, R_{t}, \tau_{t}^{l}, \pi_{t}, b_{t}, \tau_{t}^{N_{1}}, \tau_{t}^{N_{2}}, \tau_{t}^{a_{1}}, \tau_{t}^{a_{2}}, \mathbf{A}_{1 t}, \mathbf{A}_{2 t}\right\}$ to $\max -$ imize lifetime household utility (1) subject to: the consumption-leisure optimality condition (6); the Walrasian cash goods/credit goods optimality condition (7); the nominal bond Euler equation (8); the cash shopping condition (9); the credit shopping condition (10); the New Keynesian Phillips Curve (13); the cash advertising condition (18); the credit advertising condition (19); the aggregate law of motion for cash relationships (20) and credit relationships (21); the Nash pricing conditions (22) and (23); the government budget constraint (24); the valuations to firms of cash customer market and credit customer market customers (26) and (27); and the aggregate goods resource constraint (28), taking as given exogenous productivity (34) and exogenous government purchases (35).

\subsection{Computational Issues}

The first-order conditions of the Ramsey problem are assumed to be necessary and sufficient, and all allocations are assumed to be interior. As is common in the Ramsey literature, when characterizing asymptotic policy dynamics (that is, the dynamics of the Ramsey equilibrium implied by the Ramsey $t>0$ first-order conditions), we also make the auxiliary assumption that the initial state of the economy is the asymptotic Ramsey steady state.

A technical issue that arises in the formulation of the Ramsey problem is the dating of the

\footnotetext{
${ }^{11} \mathrm{We}$ also return to the case of zero lump-sum taxes, required for a Ramsey analysis.

${ }^{12}$ Thus, we follow the standard convention in Ramsey analysis that spending is exogenous but the revenue side of fiscal policy is determined optimally.
} 


\begin{tabular}{lrrrrrrr}
\hline \hline & GDP & $a$ & $x$ & $N$ & $s$ & $\theta_{1}$ & $\theta_{2}$ \\
\hline & & & & & & & \\
Abs. volatility & 2.42 & 8.39 & 2.12 & 1.96 & 4.44 & 12.43 & 12.93 \\
Rel. vol. (wrt GDP) & 1 & 3.47 & 0.88 & 0.81 & 1.84 & 5.15 & 5.35 \\
Autocorr. & 0.92 & 0.91 & 0.94 & 0.94 & 0.95 & 0.93 & 0.94 \\
Corr. wrt GDP & 1 & 0.71 & 0.58 & 0.58 & -0.82 & 0.76 & 0.75
\end{tabular}

Table 3: Business Cycle Fluctuations. Simulated moments using the estimated exogenous policy model, conditional on shocks to both productivity and government purchases.

Lagrange multiplier associated with the resource constraint (or, stated equivalently, with the government flow budget constraint). Recall from the definition of equilibrium in Section 2.7 that it is the time- $(t-1)$ resource constraint that is implied by the time- $t$ consumer and government flow budget constraints. Because the assumed timing of our model is that the Ramsey planner observes $g_{t}$ and $z_{t}$ before determining time- $t$ allocations and policies, the multiplier associated with the resource constraint is dated $t-1$ - in other words, terms in the Ramsey first-order conditions arising from the time- $t$ resource constraint carry a multiplier dated $t$. This formulation of course sounds natural, but we simply mean to point out that because of the assumed timing of markets (namely, asset markets preceding goods and labor markets), care must be taken in writing the Ramsey problem.

\subsection{Results}

Table 4 presents several long-run and short-run aspects of the Ramsey results. As the bottom panel shows, all five of the fiscal instruments (which are part of the complete set of instruments) are non-zero in the steady state, and the Friedman Rule of a zero net nominal interest rate is achieved. ${ }^{13}$ The differences between the pair $\tau^{a_{1}}$ and $\tau^{a_{2}}$ and the pair $\tau^{a_{1}}$ and $\tau^{a_{2}}$ is due to the differently estimated pricing inefficiencies across the cash customer market and the credit customer market captured in the different customer Nash bargaining powers $\eta_{1}=0.43$ and $\eta_{2}=0.46$ (as seen in Table 2), which is part of what generates congestion externalities in customer pricing.

Comparing the dynamics between Table 3 and Table 4, the volatilities of the Ramsey-optimal customer markets allocations $\theta_{1}, \theta_{2}, a\left(\equiv a_{1}+a_{2}\right)$, and $s\left(\equiv s_{1}+s_{2}\right)$ are lower than in the estimated exogenous-policy model — between 50 percent lower (for $a$ ) and 80 percent lower (for $s$ ). The reason for this is that the Ramsey government with a complete set of policy tools is able to

\footnotetext{
${ }^{13}$ As described in Section 2, all profits (dividends) received lump-sum by households are taxed at a 100-percent rate, hence the nominal interest rate plays no role in taxing them.
} 


\begin{tabular}{lrrrrrrrr}
\hline \hline & GDP & $a$ & $x$ & $N$ & $s$ & $\theta_{1}$ & $\theta_{2}$ \\
\hline & & & & & & & \\
Abs. volatility & 2.28 & 4.29 & 2.11 & 1.96 & 0.74 & 4.38 & 4.38 \\
Rel. vol. (wrt GDP) & 1 & 1.88 & 0.92 & 0.86 & 0.33 & 1.92 & 1.92 \\
Auto. corr. & 0.92 & 0.86 & 0.93 & 0.93 & 0.20 & 0.94 & 0.94 \\
Corr. with GDP & 1 & 0.63 & 0.60 & 0.60 & -0.50 & 0.70 & 0.70 \\
& & & & & & & \\
\hline \hline & & & & & & & \\
Long-run $\pi$ & 0.9924 & & & & & & \\
Long-run $\tau^{l}$ & 0.1872 & & & & & & \\
Long-run $\tau^{a_{1}}$ & 0.0398 & & & & & & \\
Long-run $\tau^{a_{2}}$ & 0.2293 & & & & & & \\
Long-run $\tau^{N_{1}}$ & -0.4858 & & & & & & \\
Long-run $\tau^{N_{2}}$ & -0.4668 & & & & & & \\
Long-run $R-1$ & 0 & & & & & \\
\hline
\end{tabular}

Table 4: Optimal Policy Allocations. Conditional on the estimated parameters, the upper panel shows Ramsey-optimal dynamics, the lower panel shows long-run Ramsey policy. Shocks are to productivity and government purchases. 
offset the congestion externalities that affect pricing in customer markets, which in turn leads to smaller fluctuations in customer markets. An important point that emerges from this is that empirically-observed fluctuations in advertising are inefficient. In term of business cycle volatilities and comovements of other aggregates - namely, GDP and consumption, which in our framework itself is broken into Walrasian consumption $x\left(\equiv x_{1}+x_{2}\right)$ and customer goods consumption $N(\equiv$ $N_{1}+N_{2}$ ) - are quite similar across the exogenous policy equilibrium and the Ramsey equilibrium.

In Table 5, the (upper) sticky-price panel and the (middle) flexible-price panel allows for comparison to the existing Ramsey literature. Focusing first just on the first three columns (inflation $\pi$, the nominal interest rate $R$, and the labor income tax $\tau^{l}$ ), comparison of row one and row four shows that the fluctuations in these instruments reproduce those in, respectively, Schmitt-Grohe and Uribe (2004) and CCK (1991). The intuition for these results is exactly as in these previous studies - with perfectly flexible nominal prices, inflation volatility acts as a shock absorber for nominal government bond payments, but for empirically-relevant nominal price rigidities, the shock absorber role is dominated by keeping pricing distortions in Walrasian markets to a minimum.

In terms of the new tax instruments (the fourth through sixth columns of Table 5), line one and line four show that the subsidies for advertising costs display similar volatilities. However, the taxes $\tau^{N_{1}}$ and $\tau^{N_{2}}$ imposed on customer market purchases are two orders of magnitude larger in the sticky-price case. From the perspective of a Social Planning problem, all of these taxes offset congestion in customer market pricing.

\subsection{Optimal Policy with Limited Tax Instruments}

The set of taxes that forms the complete set helps us to understand the model both in the positive and normative sense. However, several of these taxes $\left(\tau^{a_{1}}, \tau^{a_{2}}, \tau^{N_{1}}\right.$, and $\left.\tau^{N_{2}}\right)$ are difficult to map to observable policy, especially at business cycle frequencies. Hence, they were not included in the estimated version of the model, but introduced into the optimal policy problem as instruments for diagnostic purposes. In this section, we restrict the Ramsey planner to the same set of (incomplete) tax instruments - labor income taxes, nominal interest rates, and inflation - as was used in the estimation and examine optimal policy dynamics. Given the incompleteness, congestion externalities cannot be fully offset.

The second and fifth rows of Table 5 present results on policy volatility with incomplete tax instruments. Most striking is the large volatility of the labor income tax, regardless of sticky or flexible nominal prices. Labor tax volatility is acting as an imperfect proxy for the instruments $\left(\tau^{a_{1}}, \tau^{a_{2}}, \tau^{N_{1}}\right.$, and $\left.\tau^{N_{2}}\right)$ that directly affect customer market outcomes. In terms of the nominal interest rate, it fluctuates somewhat in both the flex-price and sticky-price cases, suggesting that monetary policy plays a somewhat greater role in stabilizing price distortions in customer markets 


\begin{tabular}{llllllll}
\hline \hline Parameter Set & $\pi_{t}$ & $R_{t}$ & $\tau_{t}^{l}$ & $\tau_{t}^{N_{1}}$ & $\tau_{t}^{N_{2}}$ & $\tau_{t}^{a_{1}}$ & $\tau_{t}^{a_{2}}$ \\
\hline
\end{tabular}

$\underline{\text { Ramsey with sticky prices }}$

$\begin{array}{llllllll}\text { Complete taxes } & 0.00 & 0.04 & 0.21 & 425.5 & 581.3 & 43.7 & 6.58 \\ \text { Incomplete taxes } & 0.00 & 0.10 & 1.74 & - & - & - & - \\ \text { Incomp. taxes + no search } & 0.00 & 0.06 & 0.52 & - & - & - & -\end{array}$

$\underline{\text { Ramsey with flexible prices }}$

\begin{tabular}{lrrrrrrr} 
Complete taxes & 6.95 & 0 & 0 & 0.92 & 0.97 & 48.5 & 7.05 \\
Incomp. taxes & 9.47 & 0.05 & 1.41 & - & - & - & - \\
& & & & & & & \\
\hline \\
\hline \hline
\end{tabular}

Table 5: Volatilities of policy instruments in several Ramsey equilibria. The incomplete system of taxes excludes $\tau^{a_{1}}, \tau^{a_{2}}, \tau^{N_{1}}$, and $\tau^{N_{2}}$. In the exogenous policy case (line 6), labor tax rate shocks are set to zero. Volatility of all instruments reported as coefficient of variation relative to that of GDP. Shocks are to TFP and government purchases. 
when the tax system is incomplete.

\subsection{Impulse Responses}

To explain further the nature of policy and allocations, we consider several impulse responses. Figure 2 shows impulse responses of search allocations to a technology shock in four different versions of the model. The starred blue line shows that the exogenous policy model generates the largest movements in search activity, both for households as well as for firms' advertising behavior which, together, translate into large movements in product market tightness. The Ramsey optimal policy with the complete set of tax instruments significantly reduces the magnitude of the impulse responses relative to the exogenous policy model, regardless of whether or not nominal rigidities are present, as shown by the dashed red and solid black lines, respectively. The green line shows that when the set of tax instruments is restricted as in Section 4.4, the Ramsey planner can only partially stabilize congestion externalities in customer markets relative to the outcome in which the full set of instruments is available. ${ }^{14}$

Figure 3 plots the impulse response of the consumption variables $x_{1}, x_{2}, N_{1}$, and $N_{2}$ to a technology shock. While the allocations for the customer goods do not depend on the presence of sticky prices, there are small but non-trivial difference in the allocations of the Walrasian goods.

Figures 4 and 5 show the impulse responses of the observable tax rates (the nominal interest rate, the labor income tax, and inflation) for a positive technology and government spending shock, respectively. Under flexible prices, the nominal interest rate and the labor tax rate remain constant at their steady-state values. In contrast, inflation is highly volatile reflecting the incentive to use ex post inflation to generate tax revenue. With nominal rigidities, the optimal response of inflation drops to nearly zero in all the other versions of the model. This is not surprising given the large welfare costs of the relative price distortion. In general, the volatility of the interest rate and the labor income tax is much higher in the model with an incomplete tax system. Comparing the response of taxes in the model with an incomplete tax system both with and without customer markets reveals that the presence of congestion frictions boosts the optimal volatility of both the interest rate as well as the labor tax.

Finally, Figure 6 provides a convenient way to summarize all of these results. Each panel of the figure presents the impulse response of one of the key wedges in our model, which the Ramsey planner attempts to stabilize with her policy. What is common across all six panels is that wedge movements in the exogenous policy model are large, as shown by the starred blue line. In the flexible price economy with a complete set of tax instruments the Ramsey planner is able to completely

\footnotetext{
${ }^{14}$ We experimented with government spending shocks and found the same qualitative results. In order to save space, we do not present these results, but they are available upon request.
} 
smooth all the wedges in the economy, as shown by the solid black line. In this special case, the Ramsey planner achieves the same dynamics as would be preferred by the social planner. (See Appendix $\mathrm{H}$ for a derivation of the social planner's problem.) The socially efficient allocations by construction internalize all congestion externalities in customer markets.

If nominal rigidities are present, the red dashed line shows that the Ramsey planner achieves outcomes that are only a tiny distance on impact from the social planner's outcomes, a difference which furthermore decays extremely quickly after the initial period. Hence, nominal price rigidities seem to have little effect on the ability of optimal policy to offset the externalities in the customer markets pricing system, so long as the tax system is complete.

When policy is restricted to a limited set of tax instruments, the planner achieves outcomes that generally lie in between the unconstrained Ramsey planner's and the exogenous policy outcome. The one exception to this is for the labor wedge (first wedge.) For this wedge, the planner does worse than under optimal policy, indicating that indeed, the planner accepts otherwise suboptimal allocations along this dimension in order to use the labor tax as an instrument to mitigate externalities in customer markets. 

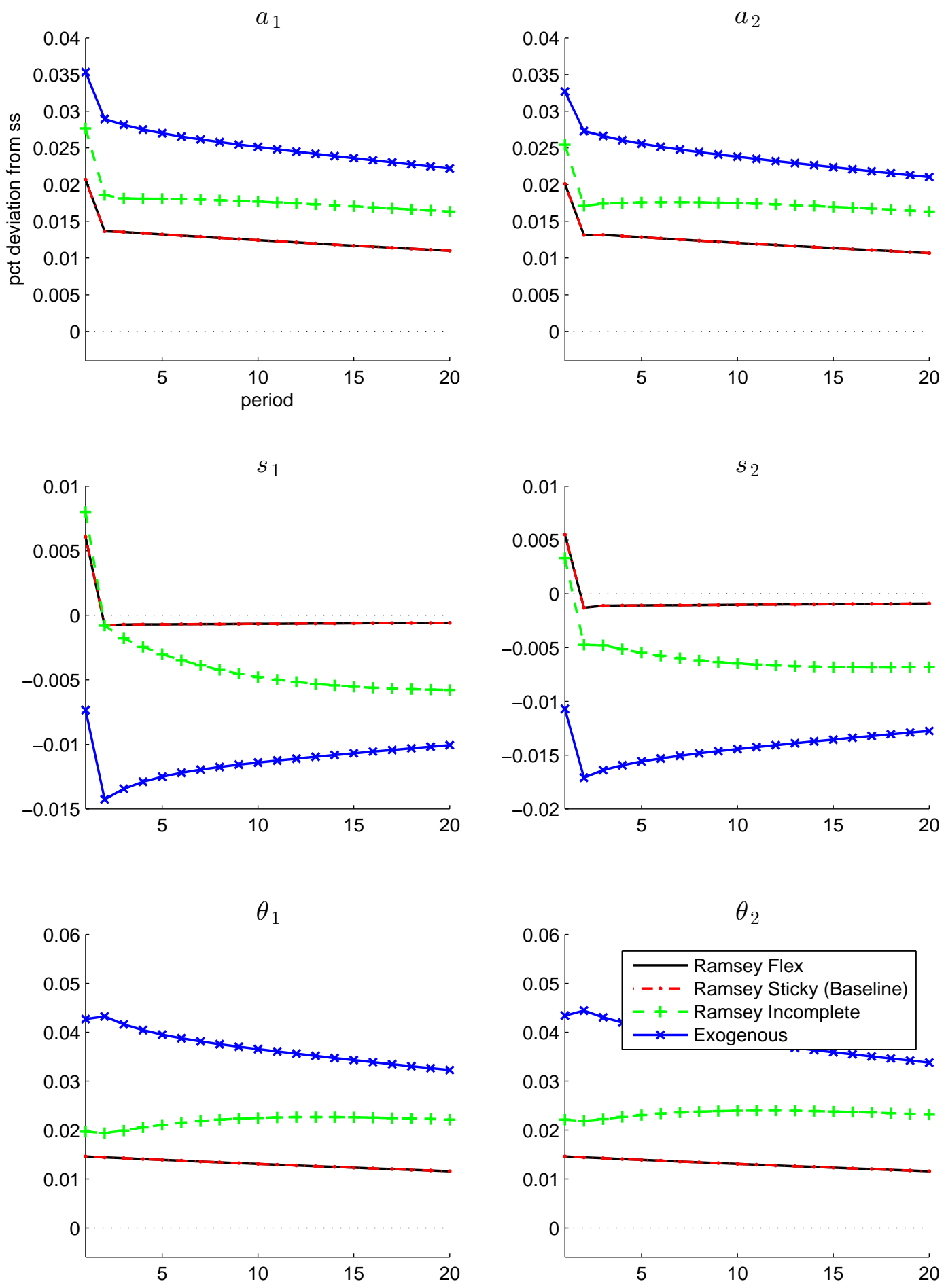

Figure 2: Search Allocations. IRFs with respect to productivity shock. 

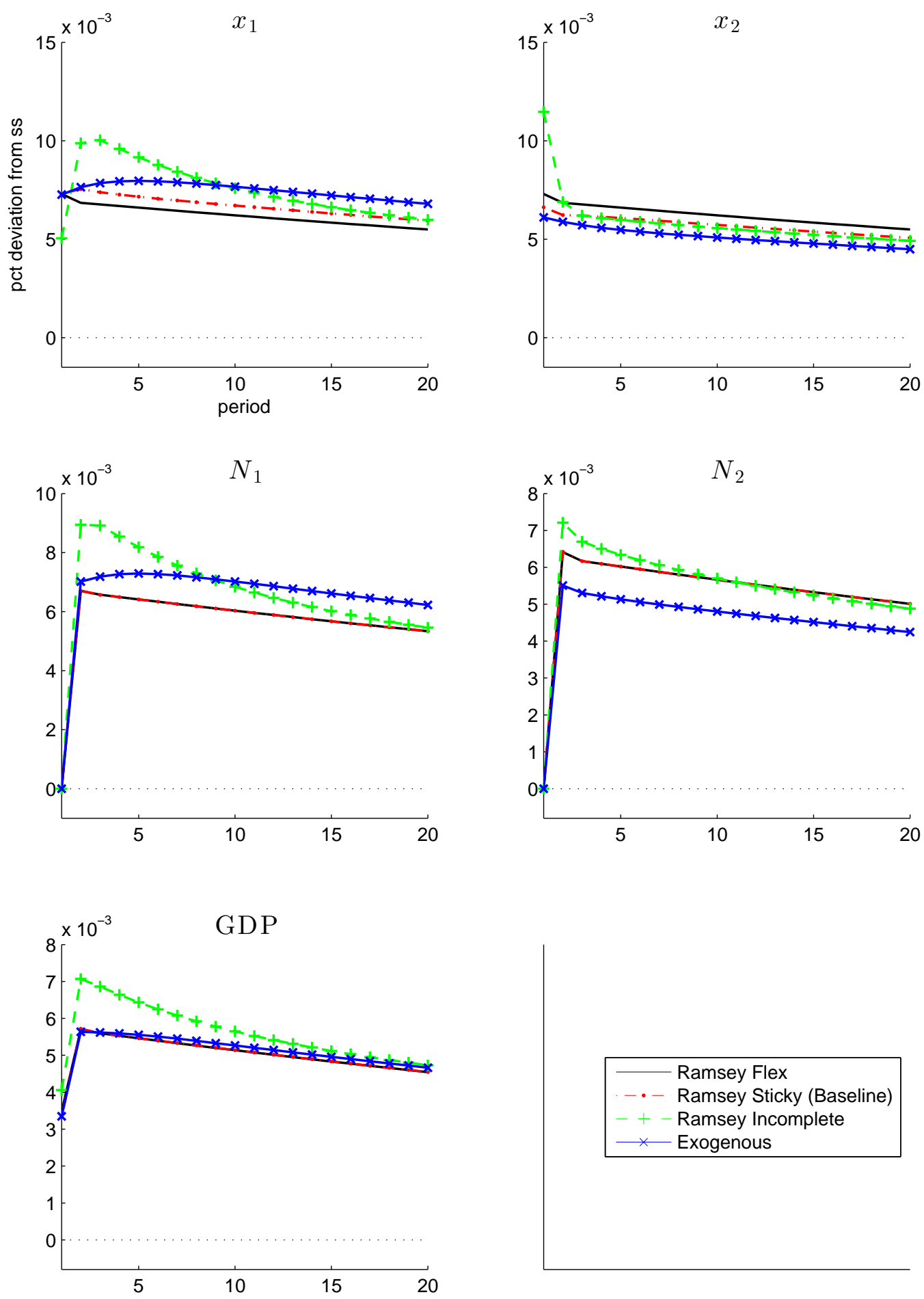

Figure 3: Macro Allocations. IRFs with respect to productivity shock. 

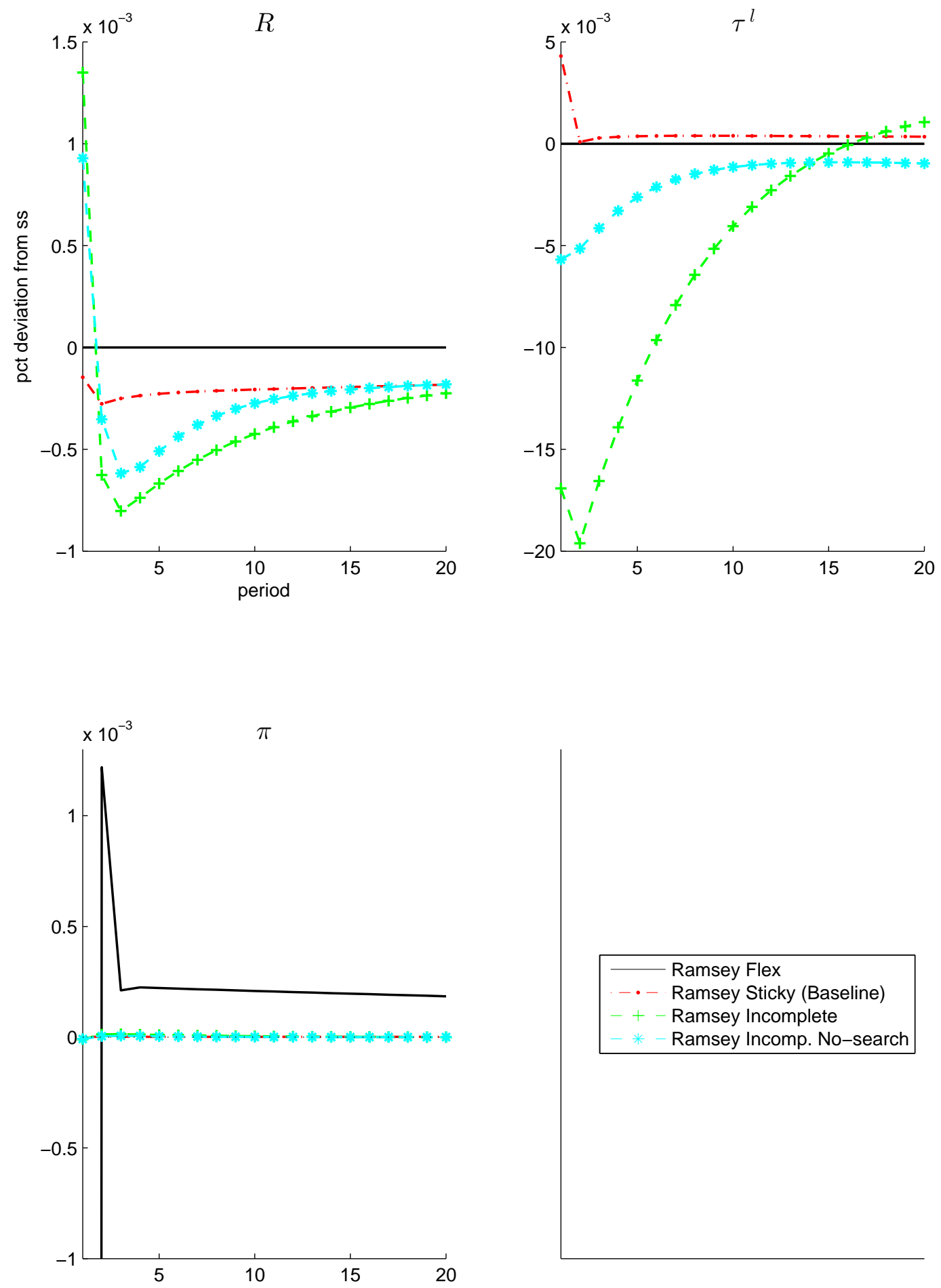

Figure 4: Taxes and TFP. Impulse responses to a government spending shock for the nominal interest rate (first panel), labor income tax (second panel), and inflation (third panel) across several equilibria. 

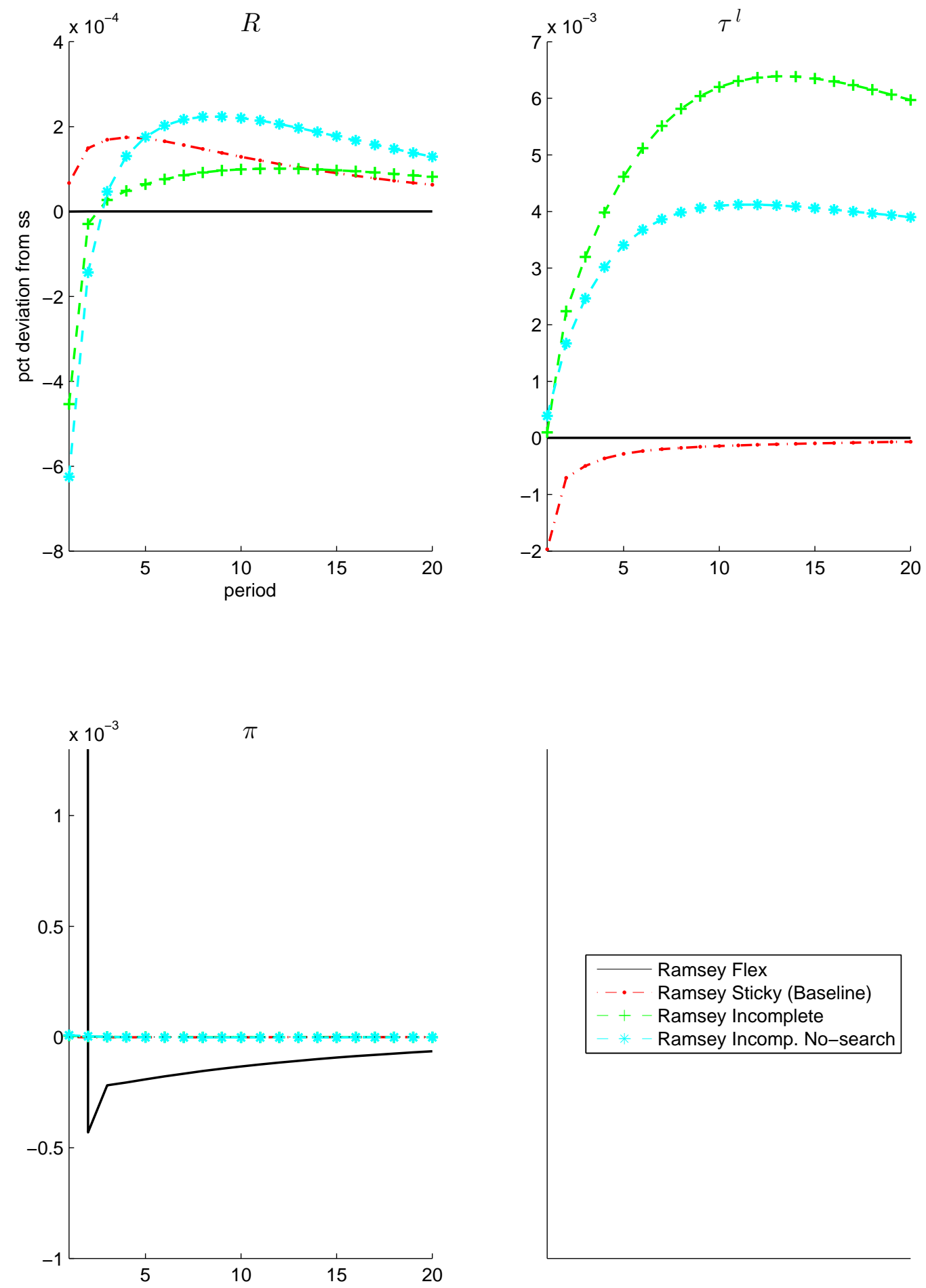

Figure 5: Taxes and Government Spending. Impulse responses to a government spending shock for the nominal interest rate (first panel), labor income tax (second panel), and inflation (third panel) across several equilibria. 

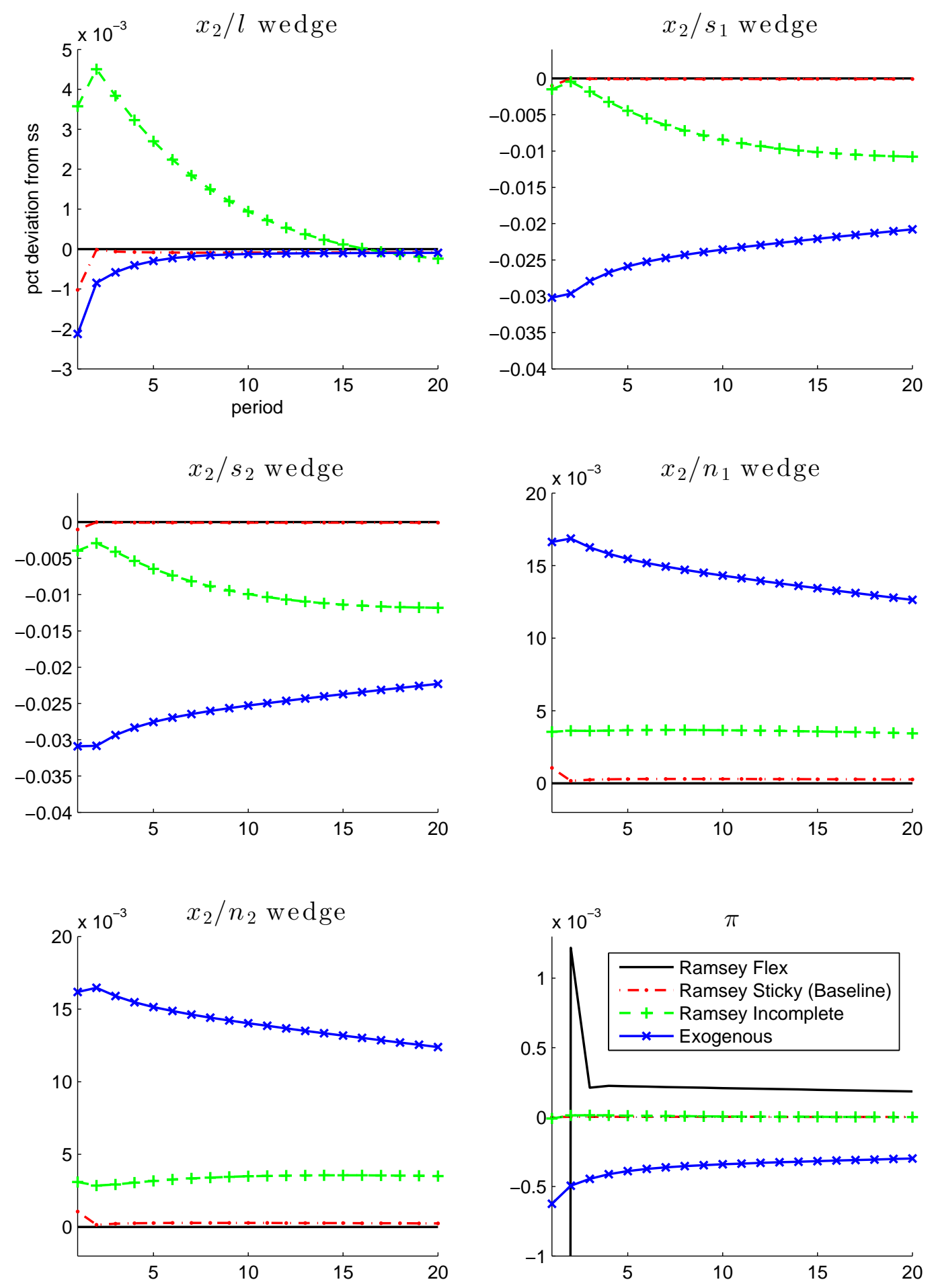

Figure 6: Wedges. Impulse responses to a TFP shock for static wedges (first three panels), intertemporal wedges (fourth and fifth panels), and inflation (sixth panel) across several equilibria. 


\section{Conclusion}

This paper estimates a model in which some fraction of goods exchange takes place in a search and matching market. The estimation process uses advertising data to pin down key parameters of the customer goods component of the model. The estimates imply strong congestion externalities in customer markets, which in turn reveal that empirically-observed advertising volatility is inefficiently large.

In light of this, a main goal of optimal policy is to dampen the externalities in customer markets. We show that if the set of instruments is constrained to a standard set of policy tools - inflation and the labor tax - then labor taxes can play a role in dampening congestion externalities in customer markets. With a complete set of tax instruments, the optimal policy mix calls for significant volatility in fiscal instruments that operate directly on the customer search market — sales taxes on customer market goods and/or advertising subsidies. Labor income taxes are constant over the business cycle, which is a classic result in the optimal policy literature that consider a complete system of taxes; however, if we consider an incomplete (but realistically observable) set of taxes, labor income taxes are strikingly volatile regardless of whether nominal prices are flexible or sticky. Whether nominal prices are flexible or sticky, the model gives very little role for monetary policy in offsetting customer-market externalities. 


\section{References}

Aguiar, Mark, Erik Hurst, and Loukas Karabarbounis. 2013. "Time Use During the Great Recession." American Economic Review, Vol. 103, pp. 1664-1696.

Arkolakis, Costas. 2010. "Market Penetration Costs and the New Consumers Margin in International Trade." Journal of Political Economy, Vol. 118, pp. 1151-1199.

Arseneau, David M. and Sanjay K. Chugh. 2012. "Tax Smoothing in Frictional Labor Markets." Journal of Political Economy, Vol. 120, pp. 926-985.

Akinci, Ozge And Ryan Chahrour. 2009. "Optimal Monetary Policy in a Model with Customer Markets." Boston College.

Cannon, Joseph P., and Christian Homburg. 2001. "Buyer-Supplier Relationships and Customer Firm Costs." Journal of Marketing, Vol. 65, pp. 29-43.

Chari, V.V., Lawrence Christiano, and Patrick Kehoe. 1991. "Optimal Fiscal and Monetary Policy: Some Recent Results." Journal of Money, Credit, and Banking, Vol. 23, pp. 519-539.

Chari V. V., and Patrick J. Kehoe. 1999. "Optimal Fiscal and Monetary Policy. In Handbook of Macroeconomics, edited by John B. Taylor and Michael Woodford, Vol. 1C. Elsevier.

Den HaAn, Wouter J. 2013. "Inventories and the Role of Goods-Market Frictions for Business Cycles." mimeo.

DurAS. 2013. "Amplification of Shocks in a Model with Labor and Goods Market Search." mimeo.

D’Erasmo, Pablo N., and Hernan J. Moscoso Boedo. 2013. "Intangibles and Endogenous Firm Volatility over the Business Cycle." mimeo.

Gourio, Francois and Leena Rudanko. 2013. "Customer Capital Review of Economic Studies." Forthcoming.

Hall, Robert E. 2008. "General Equilibrium with Customer Relationships: A Dynamic Analysis of Rent-Seeking." Stanford University.

Hall, Robert E. 2013. "What the Cyclical Response of Advertising Reveals about Markups and other Macroeconomic Wedges." Stanford University.

Hosios, Arthur J. 1990. "On the Efficiency of Matching and Related Models of Search and Unemployment." Review of Economic Studies, Vol. 57, pp. 279-298.

Leith, Campbell, Ioana Moldovan, and Raffaele Rossi. 2012. "Optimal Monetary Policy in a New Keynesian Model with Habit in Consumption." Review of Economic Dynamics, Vol. 15, pp. 416-435. 
Lester, Benjamin. 2011. "Information and Prices with Capacity Constraints." American Economic Review, Vol. 101, pp. 1591-1600.

Lucas, Robert E. JR. And Nancy L. Stokey. 1983. "Optimal Fiscal and Monetary Policy in an Economy Without Capital." Journal of Monetary Economics, Vol. 12, pp. 55-93.

Matha, Thomas Y. and Olivier Pierrard. 2011. "Search and the Product Market and the Real Business Cycle." Journal of Economic Dynamics and Control, Vol. 35, pp. 1172-1191.

Molinari, Benedetto and Francesco Turino. 2009. "Advertising and Business Cycle Fluctuations." Instituto Valenciano de Investigaciones Económicas.

Petrosky-Nadeau, Nicolas, and Etienne Wasmer. 2012. "Macroeconomic Dynamics in a Model of Goods, Labor and Credit Market Frictions." mimeo

Ravikumar, B. and Enchuan Shao. 2010. "Search Frictions and Asset Price Volatility." Bank of Canada Working Paper 2010-1.

Schmitt-Grohé, Stephanie and Martin Uribe. 2004. "Optimal Fiscal and Monetary Policy Under Sticky Prices." Journal of Economic Theory, Vol. 114, pp. 198-230.

Sheth, Jagdish N., And Reshma H. Shah. 2003. "Till death do us part... but not always: Six antecedents to a customer's relational preference in buyer-seller exchanges." Industrial Marketing Management, Vol. 32, pp. 627-631.

Siu, Henry E. 2004. "Optimal Fiscal and Monetary Policy with Sticky Prices." Journal of Monetary Economics, Vol. 51, pp. 576-607. 


\section{A Related Literature}

Relationship-based interactions between consumers and firms have recently received increasing attention in the business cycle literature. ${ }^{15}$ For example, Gourio and Rudanko (2013) study the relationship between search frictions in the goods market, firm-level dynamics, and firms' investment decisions over the business cycle. Ravikumar and Shao (2010) analyze the link between goods search frictions and the volatility of asset prices, and den Haan (2013) explores the connection between goods search frictions, inventories, and business cycles. Perhaps more relevant to our work, Hall (2008, 2013) studies the link between advertising, surplus sharing, and business cycles, highlighting that search frictions in goods markets can play an important role in explaining particular shortrun and long-run macroeconomic outcomes in the data. In particular, Hall (2013) focuses on the behavior of advertising and profit margins over the business cycle and analyzes how the role of product-market and profit margin wedges can help us reconcile the cyclical movements in profit margins with the fact that advertising is procyclical. The apparent relevance of these wedges immediately raises questions about the role of optimal policy, and this is where our work makes one relevant contribution.

Mathä and Pierrard (2011) build a business cycle model with search frictions a la Mortensen and Pissarides in the goods markets and explore whether the presence of these frictions alongside shocks to the product market improve the fit of the standard RBC model. In contrast to our setup, search frictions are present for all goods in the economy and determine the interaction between customer markets and Walrasian markets. While our model includes intermediate goods and final goods firms, there are three key differences relative to Mathä and Pierrard's work. First, we consider search frictions between consumers of final goods and firms, as opposed to search frictions between firms at different stages of production. Second, we allow for both customer goods and Walrasian goods in the economy. Thus, we can explore the implications of varying the role of customer goods in the economy for the conduct of optimal policy. Finally, our economic environment nests a standard sticky price model, which allows us to readily analyze the importance of goods search frictions relative to nominal rigidities in affecting optimal policy.

Petrosky-Nadeau and Wasmer (2012) study the business cycle consequences of having search frictions in the capital, goods, and labor markets. ${ }^{16}$ The interaction between goods and labor

\footnotetext{
${ }^{15}$ This is not the only literature that has placed attention on search frictions in the goods market. For example, some papers argue that these frictions can play an important role for firm entry and international trade, the cost structure of firms and the evolution of market size in specific sectors (Arkolakis (2010); Lester (2010); Cannon and Homburg (2001); Janssen and Non (2008)). The marketing literature has also explored how customers decide to establish long-term relationships with particular firms to acquire goods and services, while choosing to have more casual and indirect links with other rms through spot markets (Sheth and Shah (2003)).

${ }^{16}$ Using a model with labor market and goods market search frictions in general equilibrium, Duras (2013) uses
} 
market frictions establishes a novel propagation mechanism able to generate rich labor market dynamics relative to models with Walrasian goods markets. Similar to our model, the economic environment in Petrosky-Nadeau and Wasmer has two types of goods and only one of them is subject to search frictions. Moreover, the friction in the goods market affects the interaction between firms and consumers, where consumers must exert effort to find those goods subject to search frictions. In our setup, the cost of searching for goods is a time cost as opposed to an effort cost. This establishes a tradeoff between working and searching for goods that is absent in Petrosky-Nadeau and Wasmer's setup. Finally, our main focus is on the optimal policy implications of search and matching frictions in the goods market. This is an issue that Petrosky-Nadeau and Wasmer and the majority of the papers in the literature abstract from, and is one of the most important contributions of our work.

Bayesian techniques and explores whether the interaction of these two frictions can amplify productivity and demand shocks. His findings are in line with those in Petrosky-Nadeau and Wasmer (2012): the interaction between these frictions creates an amplification effect. 


\section{B Household Optimization}

The representative household maximizes expected lifetime utility

$$
\max E_{0} \sum_{t=0}^{\infty} \beta^{t}\left[u\left(x_{1 t}, x_{2 t}\right)+\vartheta v\left(N_{1 t}, N_{2 t}\right)-h\left(l_{t}+s_{1 t}+s_{2 t}\right)\right]
$$

subject to the sequence of flow budget constraints

$$
\begin{aligned}
M_{t}-M_{t-1}+B_{t}-R_{t-1} B_{t-1}= & \left(1-\tau_{t-1}^{l}\right) P_{t-1} w_{t-1} l_{t-1}-P_{t-1} x_{1 t-1} \\
& -P_{t-1} x_{2 t-1}-P_{1 t-1}\left(1+\tau_{t-1}^{N_{1}}\right) N_{1 t-1} \\
& -P_{2 t-1}\left(1+\tau_{t-1}^{N_{2}}\right) N_{2 t-1}+\left(1-\tau^{d}\right) d_{t-1} \\
& +\left[\left(1-k_{1 t-1}^{h}\right) s_{1 t-1}+\left(1-k_{2 t-1}^{h}\right) s_{2 t-1}\right] P_{t-1} \kappa
\end{aligned}
$$

cash-in-advance constraints

$$
P_{t} x_{1 t}+P_{1 t}\left(1+\tau_{t}^{N_{1}}\right) N_{1 t} \leq M_{t}
$$

and perceived laws of motion for its cash customer relationships and credit customer relationships

$$
N_{1 t+1}=(1-\rho)\left(N_{1 t}+s_{1 t} k_{1 t}^{h}\right)
$$

and

$$
N_{2 t+1}=(1-\rho)\left(N_{2 t}+s_{2 t} k_{2 t}^{h}\right)
$$

Customer goods incur the sales tax rate $\tau_{t}^{N_{1}}$ and $\tau_{t}^{N_{2}}$, and labor income is taxed at the rate $\tau_{t}^{l}$. Each unmatched shopper, whether a cash shopper or a credit shopper, receives a "coupon" $\kappa$ from the government. ${ }^{17}$ Finally, $P_{t}$ denotes the period- $t$ nominal price of any Walrasian good (cash or credit), $P_{1 t}$ denotes the period- $t$ nominal price of a cash customer good, and $P_{2 t}$ denotes the period- $t$ nominal price of credit customer good.

Denote by $\left\{\phi_{t} / P_{t-1}\right\},\left\{\lambda_{t} / P_{t}\right\},\left\{\mu_{1 t}^{h}\right\}$, and $\left\{\mu_{2 t}^{h}\right\}$ the sequences of Lagrange multipliers on the sequences of these four constraints, respectively. The first-order conditions with respect to $x_{1 t}, x_{2 t}$ $l_{t}, s_{1 t}, s_{2 t}, N_{1 t+1}, N_{2 t+1}, M_{t}$, and $B_{t}$ are, respectively,

$$
\begin{gathered}
u_{x_{1}}\left(x_{1 t}, x_{2 t}\right)-\lambda_{t}-\beta E_{t} \phi_{t+1}=0, \\
u_{x_{2}}\left(x_{1 t}, x_{2 t}\right)-\beta E_{t} \phi_{t+1}=0, \\
-h^{\prime}\left(l_{t}+s_{t}\right)+\left(1-\tau_{t}^{l}\right)\left(1+\tau_{t}^{w}\right) w_{t} \beta E_{t} \phi_{t+1}=0, \\
-h^{\prime}\left(l_{t}+s_{t}\right)+\left(1-k_{1 t}^{h}\right) \kappa \beta E_{t} \phi_{t+1}+(1-\rho) \mu_{1 t}^{h} k_{1 t}^{h}=0,
\end{gathered}
$$

\footnotetext{
${ }^{17}$ The coupon $\kappa$ could be interpreted in different ways. In this paper, we interpret them as government-provided income.
} 


$$
\begin{gathered}
-h^{\prime}\left(l_{t}+s_{t}\right)+\left(1-k_{2 t}^{h}\right) \kappa \beta E_{t} \phi_{t+1}+(1-\rho) \mu_{2 t}^{h} k_{2 t}^{h}=0 \\
-\mu_{1 t}^{h}+\beta E_{t}\left\{\vartheta v_{N_{1}}\left(N_{1 t+1}, N_{2 t+1}\right)\right\}-\beta E_{t}\left\{\lambda_{t+1} \frac{P_{1 t+1}}{P_{t+1}}\left(1+\tau_{t+1}^{N_{1}}\right)\right\}-\beta E_{t}\left\{\beta \phi_{t+2} \frac{P_{1 t+1}}{P_{t+1}}\left(1+\tau_{t+1}^{N_{1}}\right)\right\}+\beta(1-\rho) E_{t} \mu_{1 t+1}^{h} \\
-\mu_{2 t}^{h}+\beta E_{t}\left\{\vartheta v_{N_{2}}\left(N_{1 t+1}, N_{2 t+1}\right)\right\}-\beta E_{t}\left\{\beta \phi_{t+2} \frac{P_{2 t+1}}{P_{t+1}}\left(1+\tau_{t+1}^{N_{2}}\right)\right\}+\beta(1-\rho) E_{t} \mu_{2 t+1}^{h}=0 \\
-\frac{\phi_{t}}{P_{t-1}}+\frac{\lambda_{t}}{P_{t}}+\beta E_{t}\left(\frac{\phi_{t+1}}{P_{t}}\right)=0
\end{gathered}
$$

and

$$
-\frac{\phi_{t}}{P_{t-1}}+\beta R_{t} E_{t}\left(\frac{\phi_{t+1}}{P_{t}}\right)=0
$$

As in Lucas and Stokey (1983) and Chari and Kehoe (1999) and others that follow the same cash/credit setup, a standard Walrasian credit consumption-labor optimality condition arises,

$$
\frac{h^{\prime}\left(l_{t}+s_{t}\right)}{u_{x_{2}}\left(x_{1 t}, x_{2 t}\right)}=\left(1-\tau_{t}^{l}\right)\left(1+\tau_{t}^{w}\right) w_{t}
$$

(use conditions (44) and (45) to see this), a standard (Walrasian) cash-good/credit-good optimality condition arises,

$$
\frac{u_{x_{1}}\left(x_{1 t}, x_{2 t}\right)}{u_{x_{2}}\left(x_{1 t}, x_{2 t}\right)}=R_{t}
$$

and the pricing condition for the one-period nominally risk-free government bond

$$
1=R_{t} E_{t}\left[\frac{\beta u_{x_{1}}\left(x_{1 t+1}, x_{2 t+1}\right)}{u_{x_{1}}\left(x_{1 t}, x_{2 t}\right)} \frac{1}{\pi_{t+1}}\right]
$$

where $\pi_{t} \equiv P_{t} / P_{t-1}$ is the gross inflation rate between periods $t-1$ and $t$.

\section{B.1 Shopping Conditions}

We now proceed to obtain representations for, in turn, the credit shopping condition and the cash shopping condition. From here on, define $p_{1 t} \equiv P_{1 t} / P_{t}$ and $p_{2 t} \equiv P_{2 t} / P_{t}$ as the relative prices of the cash customer good and the credit customer good, respectively, and define $\Xi_{t+1 \mid t} \equiv \frac{\beta u_{x_{2}}\left(x_{1 t+1}, x_{2 t+1}\right)}{u_{x_{2}}\left(x_{1 t}, x_{2 t}\right)}$ as the one-period-ahead stochastic discount factor of the household.

\section{B.1.1 Credit Shopping Condition}

From (47), we can isolate

$$
(1-\rho) \mu_{2 t}^{h}=\frac{h^{\prime}\left(l_{t}+s_{t}\right)}{k_{2 t}^{h}}-\left(\frac{1-k_{2 t}^{h}}{k_{2 t}^{h}}\right) u_{x_{2}}\left(x_{1 t}, x_{2 t}\right) \kappa .
$$

To obtain this representation, we have used the first-order condition (44), $u_{x_{2}}\left(x_{1 t}, x_{2 t}\right)=\beta E_{t} \phi_{t+1}$, and we will continue to do so in everything that follows. 
Next, substituting this expression into (49),

$$
\begin{aligned}
& \frac{h^{\prime}\left(l_{t}+s_{t}\right)}{k_{2 t}^{h}}-\left(\frac{1-k_{2 t}^{h}}{k_{2 t}^{h}}\right) u_{x_{2}}\left(x_{1 t}, x_{2 t}\right) \kappa \\
& =(1-\rho) \beta E_{t}\left\{\vartheta v_{N_{2}}\left(N_{1 t+1}, N_{2 t+1}\right)-u_{x_{2}}\left(x_{1 t+1}, x_{2 t+1}\right)\left(1+\tau_{t+1}^{N_{2}}\right) p_{2 t+1}\right\} \\
& \quad+(1-\rho) \beta E_{t}\left\{\frac{h^{\prime}\left(l_{t+1}+s_{t+1}\right)}{k_{2 t+1}^{h}}-\left(\frac{1-k_{2 t+1}^{h}}{k_{2 t+1}^{h}}\right) u_{x_{2}}\left(x_{1 t+1}, x_{2 t+1}\right) \kappa\right\} .
\end{aligned}
$$

Dividing by $u_{x_{2}}\left(x_{1 t}, x_{2 t}\right)$ and using the notation defined above, $\Xi_{t+1 \mid t} \equiv \frac{\beta u_{x_{2}}\left(x_{1 t+1}, x_{2 t+1}\right)}{u_{x_{2}}\left(x_{1 t}, x_{2 t}\right)}$,

$$
\begin{aligned}
& \frac{h^{\prime}\left(l_{t}+s_{t}\right)}{u_{x_{2}}\left(x_{1 t}, x_{2 t}\right)} \frac{1}{k_{2 t}^{h}}-\left(\frac{1-k_{2 t}^{h}}{k_{2 t}^{h}}\right) \kappa \\
& \quad=(1-\rho) E_{t}\left\{\Xi_{t+1 \mid t}\left[\frac{\vartheta v_{N_{2}}\left(N_{1 t+1}, N_{2 t+1}\right)}{u_{x_{2}}\left(x_{1 t+1}, x_{2 t+1}\right)}-\left(1+\tau_{t+1}^{N_{2}}\right) p_{2 t+1}+\frac{h^{\prime}\left(l_{t+1}+s_{t+1}\right)}{u_{x_{2}}\left(x_{1 t+1}, x_{2 t+1}\right)} \frac{1}{k_{2 t+1}^{h}}-\left(\frac{1-k_{2 t+1}^{h}}{k_{2 t+1}^{h}}\right) \kappa\right]\right\},
\end{aligned}
$$

which is a representation of the credit shopping condition condition that is useful for the creditrelationship Nash bargaining problem below because it is recursive in the term

$$
\frac{h^{\prime}\left(l_{t}+s_{t}\right)}{u_{x_{2}}\left(x_{1 t}, x_{2 t}\right)} \frac{1}{k_{2 t}^{h}}-\left(\frac{1-k_{2 t}^{h}}{k_{2 t}^{h}}\right) \kappa .
$$

\section{B.1.2 Cash Shopping Condition}

For the cash shopping condition, start by proceeding similarly: from (46), we can isolate

$$
(1-\rho) \mu_{1 t}^{h}=\frac{h^{\prime}\left(l_{t}+s_{t}\right)}{k_{1 t}^{h}}-\left(\frac{1-k_{1 t}^{h}}{k_{1 t}^{h}}\right) u_{x_{2}}\left(x_{1 t}, x_{2 t}\right) \kappa .
$$

Next, substituting this expression into (48),

$$
\begin{aligned}
& \frac{h^{\prime}\left(l_{t}+s_{t}\right)}{k_{1 t}^{h}}-\left(\frac{1-k_{1 t}^{h}}{k_{1 t}^{h}}\right) u_{x_{2}}\left(x_{1 t}, x_{2 t}\right) \kappa \\
& =(1-\rho) \beta E_{t}\left\{\vartheta v_{N_{1}}\left(N_{1 t+1}, N_{2 t+1}\right)-p_{1 t+1}\left(1+\tau_{t+1}^{N_{1}}\right)\left[\beta \phi_{t+2}+\lambda_{t+1}\right]\right\} \\
& \quad+(1-\rho) \beta E_{t}\left\{\frac{h^{\prime}\left(l_{t+1}+s_{t+1}\right)}{k_{1 t+1}^{h}}-\left(\frac{1-k_{1 t+1}^{h}}{k_{1 t+1}^{h}}\right) u_{x_{2}}\left(x_{1 t+1}, x_{2 t+1}\right) \kappa\right\} .
\end{aligned}
$$

Use (43) (and the law of iterated expectations) to substitute into the second line, which gives

$$
\begin{aligned}
& \frac{h^{\prime}\left(l_{t}+s_{t}\right)}{k_{1 t}^{h}}-\left(\frac{1-k_{1 t}^{h}}{k_{1 t}^{h}}\right) u_{x_{2}}\left(x_{1 t}, x_{2 t}\right) \kappa \\
& =(1-\rho) \beta E_{t}\left\{\vartheta v_{N_{1}}\left(N_{1 t+1}, N_{2 t+1}\right)-p_{1 t+1}\left(1+\tau_{t+1}^{N_{1}}\right) u_{x_{1}}\left(x_{1 t+1}, x_{2 t+1}\right)\right\} \\
& \quad+(1-\rho) \beta E_{t}\left\{\frac{h^{\prime}\left(l_{t+1}+s_{t+1}\right)}{k_{1 t+1}^{h}}-\left(\frac{1-k_{1 t+1}^{h}}{k_{1 t+1}^{h}}\right) u_{x_{2}}\left(x_{1 t+1}, x_{2 t+1}\right) \kappa\right\} .
\end{aligned}
$$


Next, divide this expression by $u_{x_{2}}\left(x_{1 t}, x_{2 t}\right)$, which yields

$$
\begin{aligned}
& \frac{h^{\prime}\left(l_{t}+s_{t}\right)}{u_{x_{2}}\left(x_{1 t}, x_{2 t}\right)} \frac{1}{k_{1 t}^{h}}-\left(\frac{1-k_{1 t}^{h}}{k_{1 t}^{h}}\right) \cdot \kappa \\
& \quad=(1-\rho) \beta E_{t}\left\{\frac{\vartheta v_{N_{1}}\left(N_{1 t+1}, N_{2 t+1}\right)}{u_{x_{2}}\left(x_{1 t}, x_{2 t}\right)}-p_{1 t+1}\left(1+\tau_{t+1}^{N_{1}}\right) \frac{u_{x_{1}}\left(x_{1 t+1}, x_{2 t+1}\right)}{u_{x_{2}}\left(x_{1 t}, x_{2 t}\right)}\right\} \\
& \quad+(1-\rho) \beta E_{t}\left\{\frac{h^{\prime}\left(l_{t+1}+s_{t+1}\right)}{u_{x_{2}}\left(x_{1 t}, x_{2 t}\right)} \frac{1}{k_{1 t+1}^{h}}-\left(\frac{1-k_{1 t+1}^{h}}{k_{1 t+1}^{h}}\right) \frac{u_{x_{2}}\left(x_{1 t+1}, x_{2 t+1}\right)}{u_{x_{2}}\left(x_{1 t}, x_{2 t}\right)} \cdot \kappa\right\} .
\end{aligned}
$$

Multiply and divide the second line and third line above by $u_{x_{2}}\left(x_{1 t+1}, x_{2 t+1}\right)$, which gives

$$
\begin{aligned}
& \frac{h^{\prime}\left(l_{t}+s_{t}\right)}{u_{x_{2}}\left(x_{1 t}, x_{2 t}\right)} \frac{1}{k_{1 t}^{h}}-\left(\frac{1-k_{1 t}^{h}}{k_{1 t}^{h}}\right) \cdot \kappa \\
& \quad=(1-\rho) \beta E_{t}\left\{\frac{u_{x_{2}}\left(x_{1 t+1}, x_{2 t+1}\right)}{u_{x_{2}}\left(x_{1 t}, x_{2 t}\right)} \frac{\vartheta v_{N_{1}}\left(N_{1 t+1}, N_{2 t+1}\right)}{u_{x_{2}}\left(x_{1 t+1}, x_{2 t+1}\right)}-p_{1 t+1}\left(1+\tau_{t+1}^{N_{1}}\right) \frac{u_{x_{1}}\left(x_{1 t+1}, x_{2 t+1}\right)}{u_{x_{2}}\left(x_{1 t+1}, x_{2 t+1}\right)} \frac{u_{x_{2}}\left(x_{1 t+1}, x_{2 t+1}\right)}{u_{x_{2}}\left(x_{1 t}, x_{2 t}\right)}\right\} \\
& \quad+(1-\rho) \beta E_{t}\left\{\frac{h^{\prime}\left(l_{t+1}+s_{t+1}\right)}{u_{x_{2}}\left(x_{1 t+1}, x_{2 t+1}\right)} \frac{u_{x_{2}}\left(x_{1 t+1}, x_{2 t+1}\right)}{u_{x_{2}}\left(x_{1 t}, x_{2 t}\right)} \frac{1}{k_{1 t+1}^{h}}-\left(\frac{1-k_{1 t+1}^{h}}{k_{1 t+1}^{h}}\right) \frac{u_{x_{2}}\left(x_{1 t+1}, x_{2 t+1}\right)}{u_{x_{2}}\left(x_{1 t}, x_{2 t}\right)} \cdot \kappa\right\} .
\end{aligned}
$$

Collecting terms,

$$
\begin{aligned}
& \frac{h^{\prime}\left(l_{t}+s_{t}\right)}{u_{x_{2}}\left(x_{1 t}, x_{2 t}\right)} \frac{1}{k_{1 t}^{h}}-\left(\frac{1-k_{1 t}^{h}}{k_{1 t}^{h}}\right) \cdot \kappa \\
& \quad=(1-\rho) E_{t}\left\{\frac{\beta u_{x_{2}}\left(x_{1 t+1}, x_{2 t+1}\right)}{u_{x_{2}}\left(x_{1 t}, x_{2 t}\right)}\left[\frac{\vartheta v_{N_{1}}\left(N_{1 t+1}, N_{2 t+1}\right)}{u_{x_{2}}\left(x_{1 t+1}, x_{2 t+1}\right)}-p_{1 t+1}\left(1+\tau_{t+1}^{N_{1}}\right) \frac{u_{x_{1}}\left(x_{1 t+1}, x_{2 t+1}\right)}{u_{x_{2}}\left(x_{1 t+1}, x_{2 t+1}\right)}\right]\right\} \\
& \quad+(1-\rho) E_{t}\left\{\frac{\beta u_{x_{2}}\left(x_{1 t+1}, x_{2 t+1}\right)}{u_{x_{2}}\left(x_{1 t}, x_{2 t}\right)}\left[\frac{h^{\prime}\left(l_{t+1}+s_{t+1}\right)}{u_{x_{2}}\left(x_{1 t+1}, x_{2 t+1}\right)} \frac{1}{k_{1 t+1}^{h}}-\left(\frac{1-k_{1 t+1}^{h}}{k_{1 t+1}^{h}}\right) \kappa\right]\right\} .
\end{aligned}
$$

Finally, use the notation $\Xi_{t+1 \mid t}$, and also note that we can substitute $R_{t+1}$ on the right-hand side. Thus, the cash shopping condition is

$$
\begin{aligned}
& \frac{h^{\prime}\left(l_{t}+s_{t}\right)}{u_{x_{2}}\left(x_{1 t}, x_{2 t}\right)} \frac{1}{k_{1 t}^{h}}-\left(\frac{1-k_{1 t}^{h}}{k_{1 t}^{h}}\right) \kappa \\
& \quad=(1-\rho) E_{t}\left\{\Xi_{t+1 \mid t}\left[\frac{\vartheta v_{N_{1}}\left(N_{1 t+1}, N_{2 t+1}\right)}{u_{x_{2}}\left(x_{1 t+1}, x_{2 t+1}\right)}-p_{1 t+1} R_{t+1}\left(1+\tau_{t+1}^{N_{1}}\right)+\frac{h^{\prime}\left(l_{t+1}+s_{t+1}\right)}{u_{x_{2}}\left(x_{1 t+1}, x_{2 t+1}\right)} \frac{1}{k_{1 t+1}^{h}}-\left(\frac{1-k_{1 t+1}^{h}}{k_{1 t+1}^{h}}\right) \kappa\right]\right\}
\end{aligned}
$$

and this particular representation is useful for the cash-relationship Nash bargaining problem below because it is recursive in the term

$$
\frac{h^{\prime}\left(l_{t}+s_{t}\right)}{u_{x_{2}}\left(x_{1 t}, x_{2 t}\right)} \frac{1}{k_{1 t}^{h}}-\left(\frac{1-k_{1 t}^{h}}{k_{1 t}^{h}}\right) \kappa .
$$




\section{B.1.3 Envelope Conditions}

For the Nash bargaining problems below, define the value function associated with the household problem as $\mathbf{V}\left(N_{1 t}, N_{2 t}\right)$. The associated period- $t$ envelope conditions are thus

$$
\begin{aligned}
\mathbf{V}_{N_{1}}\left(N_{1 t}, N_{2 t}\right) & =\vartheta v_{N_{1}}\left(N_{1 t}, N_{2 t}\right)-p_{1 t}\left(1+\tau_{t}^{N_{1}}\right)\left[\beta E_{t} \phi_{t+1}+\lambda_{t}\right]+(1-\rho) \mu_{1 t}^{h} \\
& =\vartheta v_{N_{1}}\left(N_{1 t}, N_{2 t}\right)-u_{x_{1}}\left(x_{1 t}, x_{2 t}\right) p_{1 t}\left(1+\tau_{t}^{N_{1}}\right)+\frac{h^{\prime}\left(l_{t}+s_{t}\right)}{k_{1 t}^{h}}-\left(\frac{1-k_{1 t}^{h}}{k_{1 t}^{h}}\right) u_{x_{2}}\left(x_{1 t}, x_{2 t}\right) \kappa
\end{aligned}
$$

for the cash non-Walrasian good, in which the second line follows from (59); and for the credit non-Walrasian good,

$$
\begin{aligned}
\mathbf{V}_{N_{2}}\left(N_{1 t}, N_{2 t}\right) & =\vartheta v_{N_{2}}\left(N_{1 t}, N_{2 t}\right)-\left(1+\tau_{t}^{N_{2}}\right) p_{2 t} \beta E_{t} \phi_{t+1}+(1-\rho) \mu_{2 t}^{h} \\
& =\vartheta v_{N_{2}}\left(N_{1 t}, N_{2 t}\right)-u_{x_{2}}\left(x_{1 t}, x_{2 t}\right)\left(1+\tau_{t}^{N_{2}}\right) p_{2 t}+\frac{h^{\prime}\left(l_{t}+s_{t}\right)}{k_{2 t}^{h}}-\left(\frac{1-k_{2 t}^{h}}{k_{2 t}^{h}}\right) u_{x_{2}}\left(x_{1 t}, x_{2 t}\right) \kappa
\end{aligned}
$$

in which the second line follows from (55). For use in the Nash bargaining problems below, the period $t+1$ envelope conditions can be expressed in discounted terms, respectively, as

$\Xi_{t+1 \mid t} \frac{\mathbf{V}_{N_{1}}\left(N_{1 t+1}, N_{2 t+1}\right)}{u_{x_{2}}\left(x_{1 t+1}, x_{2 t+1}\right)}=\Xi_{t+1 \mid t}\left[\frac{\vartheta v_{N_{1}}\left(N_{1 t}, N_{2 t}\right)}{u_{x_{2}}\left(x_{1 t+1}, x_{2 t+1}\right)}-p_{1 t+1} R_{t+1}\left(1+\tau_{t+1}^{N_{1}}\right)+\frac{h^{\prime}\left(l_{t+1}+s_{t+1}\right)}{u_{x_{2}}\left(x_{1 t+1}, x_{2 t+1}\right)} \frac{1}{k_{1 t+1}^{h}}-\left(\frac{1-k_{1 t+}^{h}}{k_{1 t+1}^{h}}\right.\right.$

and

$\Xi_{t+1 \mid t} \frac{\mathbf{V}_{N_{2}}\left(N_{1 t+1}, N_{2 t+1}\right)}{u_{x_{2}}\left(x_{1 t+1}, x_{2 t+1}\right)}=\Xi_{t+1 \mid t}\left[\frac{\vartheta v_{N_{2}}\left(N_{1 t}, N_{2 t}\right)}{u_{x_{2}}\left(x_{1 t+1}, x_{2 t+1}\right)}-\left(1+\tau_{t+1}^{N_{2}}\right) p_{2 t+1}+\frac{h^{\prime}\left(l_{t+1}+s_{t+1}\right)}{u_{x_{2}}\left(x_{1 t+1}, x_{2 t+1}\right)} \frac{1}{k_{2 t+1}^{h}}-\left(\frac{1-k_{2 t+1}^{h}}{k_{2 t+1}^{h}}\right) \kappa\right.$ 


\section{Firm Optimization}

\section{C.1 Final Goods Firms}

Final goods that are sold to households, through either Walrasian markets or non-Walrasian search and matching markets, are produced via Dixit-Stiglitz bundling of intermediate goods. The price elasticity of demand for each of the intermediate goods is $\varepsilon$, and thus the elasticity of demand across intermediate producers will be $\frac{\varepsilon-1}{\varepsilon}$. As is well-known, the equilibrium markup for Walrasian-market final goods will be $\frac{\varepsilon}{\varepsilon-1}$. However, the equilibrium markup for search-and-matching final goods will also depend on the bargaining power of customers versus firms, as well as on tax rates.

\section{C.1.1 Walrasian Final Goods Firms}

Each Walrasian final goods firm $j$ produces output according to the CES production function

$$
X_{j, t}=\left(\int x_{i, t}^{\frac{\varepsilon-1}{\varepsilon}} d i\right)^{\frac{\varepsilon}{\varepsilon-1}}
$$

in which $x_{i, t}$ represents units of intermediate good $i$ used in the production of Walrasian goods. ${ }^{18}$ In symmetric equilibrium, each firm $j$ sells its output in a competitive market, so that $X_{j, t}=X_{j^{\prime}, t}=$ $X_{t}$, for $j \neq j^{\prime}$. Cost minimization implies that

$$
x_{i, t}=\left(\frac{p_{i, t}}{P_{t}}\right)^{-\varepsilon} X_{t},
$$

where $P_{t}$ is the price of a unit of the Walrasian good $X_{t}$.

\section{C.1.2 Customer Market Firms}

Each final goods firm $j$ in the search sector produces according to the CES technology. Its output is given by

$$
C_{j, t}=\left(\int c_{i, t}^{\frac{\varepsilon-1}{\varepsilon}} d i\right)^{\frac{\varepsilon}{\varepsilon-1}}
$$

in which $c_{i, t}$ represents the quantity of intermediate good $i$ used in the production of customer goods. In symmetric equilibrium, each search firm $j$ produces $C_{j, t}=C_{j^{\prime}, t}=C_{t}$, for all $j \neq j^{\prime}$. Cost minimization again implies that

$$
c_{i, t}=\left(\frac{p_{i, t}}{P_{t}}\right)^{-\varepsilon} C_{t}
$$

in which $P_{t}$ is the price of the Walrasian good used to produce (excluding search-and-matching related costs) a unit of the customer good. This can equivalently be thought about as the marginal cost $m c_{t}$ of producing a unit of the customer good. ${ }^{19}$

\footnotetext{
${ }^{18}$ Note that $x, p$, and $X$ are chosen to describe the firm-level problems in this section. Thus, for example, $p_{j, t}$ denotes the nominal price chosen by final goods producer $j$; it does not denote the Nash-bargained prices $p_{1 t}$ or $p_{2 t}$.

${ }^{19}$ When we later impose symmetric equilibrium and normalize by nominal $P_{t}$, we will have $P_{t}=m c_{t}=1$.
} 
Each customer match in which the customer and firm agree to a price and hence trade (whether a cash customer or a credit customer) yields one unit of consumption/output, so that $C_{1 t}=N_{1 t}$ (for cash customers) and $C_{2 t}=N_{2 t}$ (for credit customers). Thus, the representative search firm maximizes

$$
\max _{N_{1 t+1}, N_{2 t+1}, a_{1 t}, a_{2 t}} E_{0} \sum_{t=0}^{\infty} \Xi_{t \mid 0}\left[\left(p_{1 t}-1\right) N_{1 t}+\left(p_{2 t}-1\right) N_{2 t}-\left(1-\tau_{t}^{a_{1}}\right) \gamma_{1} a_{1 t}-\left(1-\tau_{t}^{a_{2}}\right) \gamma_{2} a_{2 t}\right]
$$

subject to perceived laws of motion

$$
N_{1 t+1}=(1-\rho)\left(N_{1 t}+k_{1 t}^{f} a_{1 t}\right)
$$

and

$$
N_{2 t+1}=(1-\rho)\left(N_{2 t}+k_{2 t}^{f} a_{2 t}\right) .
$$

The nominal price for a search cash (credit) good is $P_{1 t}\left(P_{2 t}\right), k_{1 t}^{f}\left(k_{2 t}^{f}\right)$ is the probability of a given advertisement yielding a cash (credit) match, $a_{1 t}\left(a_{2 t}\right)$ is advertising to attract cash (credit) matches, and $\gamma_{1}\left(\gamma_{2}\right)$ parameterizes the cost of cash (credit) advertising.

Defining $\mu_{1 t}^{f}$ and $\mu_{2 t}^{f}$ as the Lagrange multipliers with respect to the evolution of its cash customer base and its credit customer base, the first-order conditions with respect to $a_{1 t}, a_{2 t}$, $N_{1 t+1}$, and $N_{2 t+1}$, respectively, are

$$
\begin{gathered}
-\left(1-\tau_{t}^{a_{1}}\right) \gamma_{1}+\mu_{1 t}^{f}(1-\rho) k_{1 t}^{f}=0 \\
-\left(1-\tau_{t}^{a_{2}}\right) \gamma_{2}+\mu_{2 t}^{f}(1-\rho) k_{2 t}^{f}=0 \\
-\mu_{1 t}^{f}+E_{t}\left\{\Xi_{t+1 \mid t}\left(p_{1 t+1}-1+(1-\rho) \mu_{1 t+1}^{f}\right)\right\}=0,
\end{gathered}
$$

and

$$
-\mu_{2 t}^{f}+E_{t}\left\{\Xi_{t+1 \mid t}\left(p_{2 t+1}-1+(1-\rho) \mu_{2 t+1}^{f}\right)\right\}=0
$$

Conditions (78) and (80) give the firm's optimal advertising condition for cash matches

$$
\frac{\left(1-\tau_{t}^{a_{1}}\right) \gamma_{1}}{k_{1 t}^{f}}=(1-\rho) E_{t}\left\{\Xi_{t+1 \mid t}\left(p_{1 t+1}-1+\frac{\left(1-\tau_{t+1}^{a_{1}}\right) \gamma_{1}}{k_{1 t+1}^{f}}\right)\right\},
$$

while (79) and (81) gives the firm's optimal advertising condition for credit matches

$$
\frac{\left(1-\tau_{t}^{a_{2}}\right) \gamma_{2}}{k_{2 t}^{f}}=(1-\rho) E_{t}\left\{\Xi_{t+1 \mid t}\left(p_{2 t+1}-1+\frac{\left(1-\tau_{t+1}^{a_{2}}\right) \gamma_{2}}{k_{2 t+1}^{f}}\right)\right\} .
$$

Note that a firm's allocation of total advertising across cash and credit markets is described by

$$
\frac{E_{t}\left\{\Xi_{t+1 \mid t}\left(p_{1 t+1}-1+\frac{\left(1-\tau_{t+1}^{a_{1}}\right) \gamma_{1}}{k_{1 t+1}^{f}}\right)\right\}}{E_{t}\left\{\Xi_{t+1 \mid t}\left(p_{2 t+1}-1+\frac{\left(1-\tau_{t+1}^{a_{2}}\right) \gamma_{2}}{k_{2 t+1}^{f}}\right)\right\}}=\frac{k_{2 t}^{f}}{k_{1 t}^{f}} \cdot \frac{\gamma_{1}}{\gamma_{2}} \cdot \frac{1-\tau_{t}^{a_{1}}}{1-\tau_{t}^{a_{2}}},
$$


which depends on $\theta_{1 t} / \theta_{2 t}$.

For the Nash bargaining problems below, define the value function (denoted in Walrasian goods) associated with the firm problem as $\mathbf{F}\left(N_{1 t}, N_{2 t}\right)$. The associated period- $t$ envelope conditions are thus

$$
\begin{aligned}
\mathbf{F}_{N_{1}}\left(N_{1 t}, N_{2 t}\right) & =p_{1 t}-1+(1-\rho) \mu_{1 t}^{f} \\
& =p_{1 t}-1+\frac{\left(1-\tau_{t}^{a_{1}}\right) \gamma_{1}}{k_{1 t}^{f}},
\end{aligned}
$$

for cash customer good, in which the second line follows from (78); and for the credit customer good,

$$
\begin{aligned}
\mathbf{F}_{N_{2}}\left(N_{1 t}, N_{2 t}\right) & =p_{2 t}-1+(1-\rho) \mu_{2 t}^{f} \\
& =p_{2 t}-1+\frac{\left(1-\tau_{t}^{a_{2}}\right) \gamma_{2}}{k_{2 t}^{f}},
\end{aligned}
$$

in which the second line follows from (79).

Finally, for use in the Nash bargaining problem below, the period $t+1$ envelope conditions can be expressed in discounted terms, respectively, as

$$
\Xi_{t+1 \mid t} \mathbf{F}_{N_{1}}\left(N_{1 t}, N_{2 t}\right)=\Xi_{t+1 \mid t}\left[p_{1 t+1}-1+\frac{\left(1-\tau_{t+1}^{a_{1}}\right) \gamma_{1}}{k_{1 t+1}^{f}}\right]
$$

and

$$
\Xi_{t+1 \mid t} \mathbf{F}_{N_{2}}\left(N_{1 t}, N_{2 t}\right)=\Xi_{t+1 \mid t}\left[p_{2 t+1}-1+\frac{\left(1-\tau_{t+1}^{a_{2}}\right) \gamma_{2}}{k_{2 t+1}^{f}}\right] .
$$




\section{Nash-Bargained Prices}

\section{D.1 Value Equations for Household}

An individual who did not find a match at which to purchase goods in period $t$ [receives "coupons" $\kappa]$ has value (measured in terms of Walrasian goods) to the household

$$
\mathbf{S}_{t}=\kappa \text {. }
$$

There is zero continuation payoff to the household of an unmatched shopper because the household re-optimizes searching for goods at the start of period $t+1$, and $s_{t}$ is not a state variable for the household at the start of period $t+1$. Thus, the trivial "envelope condition" with respect to $s_{t}$ is simply the outside payoff $\kappa$.

\section{D.1.1 Credit Matches}

An individual who is a credit customer (whether a first-time customer or a long-time customer) in period $t$ has value (measured in terms of Walrasian goods) to the household

$$
\mathbf{M}_{2 t}=\frac{\vartheta v_{N_{2}}\left(N_{1 t}, N_{2 t}\right)}{u_{x_{2}}\left(x_{1 t}, x_{2 t}\right)}-\left(1+\tau_{t}^{N_{2}}\right) p_{2 t}+(1-\rho) E_{t}\left\{\Xi_{t+1 \mid t} \frac{\mathbf{V}_{N_{2}}\left(N_{1 t+1}, N_{2 t+1}\right)}{u_{x_{2}}\left(x_{1 t}, x_{2 t}\right)}\right\} .
$$

The payoffs are utility net of the after-tax bargained payment, in addition to the marginal value to the household of entering period $t+1$ with another pre-existing credit customer relationship, which is measured by the household-level envelope condition.

The surplus from purchasing via credit at a firm is thus

$$
\begin{aligned}
\mathbf{M}_{2 t}-\mathbf{S}_{t} & =\frac{\vartheta v_{N_{2}}\left(N_{1 t}, N_{2 t}\right)}{u_{x_{2}}\left(x_{1 t}, x_{2 t}\right)}-\left(1+\tau_{t}^{N_{2}}\right) p_{2 t}-\kappa+(1-\rho) E_{t}\left\{\Xi_{t+1 \mid t} \frac{\mathbf{V}_{N_{2}}\left(N_{1 t+1}, N_{2 t+1}\right)}{u_{x_{2}}\left(x_{1 t}, x_{2 t}\right)}\right\} \\
& =\frac{\vartheta v_{N_{2}}\left(N_{1 t}, N_{2 t}\right)}{u_{x_{2}}\left(x_{1 t}, x_{2 t}\right)}-\left(1+\tau_{t}^{N_{2}}\right) p_{2 t}-\kappa+(1-\rho) E_{t}\left\{\Xi_{t+1 \mid t}\left[\frac{\vartheta v_{N_{2}}\left(N_{1 t+1}, N_{2 t+1}\right)}{u_{x_{2}}\left(x_{1 t+1}, x_{2 t+1}\right)}-\left(1+\tau_{t+1}^{N_{2}}\right) p_{2 t+1}\right]\right\} \\
& +(1-\rho) E_{t}\left\{\Xi_{t+1 \mid t}\left[\frac{h^{\prime}\left(l_{t+1}+s_{t+1}\right)}{u_{x_{2}}\left(x_{1 t+1}, x_{2 t+1}\right)} \frac{1}{k_{2 t+1}^{h}}-\left(\frac{1-k_{2 t+1}^{h}}{k_{2 t+1}^{h}}\right) \kappa\right]\right\},
\end{aligned}
$$

in which the second line makes use of the envelope condition (70). Comparing (91) to condition (70), it is clear that

$$
\mathbf{M}_{2 t}-\mathbf{S}_{t}=\frac{h^{\prime}\left(l_{t}+s_{t}\right)}{u_{x_{2}}\left(x_{1 t}, x_{2 t}\right)} \frac{1}{k_{2 t}^{h}}-\left(\frac{1-k_{2 t}^{h}}{k_{2 t}^{h}}\right) \kappa .
$$

The surplus earned by the household of successfully completing a purchase of credit customer goods can finally be expressed as

$$
\mathbf{M}_{2 t}-\mathbf{S}_{t}=\frac{\vartheta v_{N_{2}}\left(N_{1 t}, N_{2 t}\right)}{u_{x_{2}}\left(x_{1 t}, x_{2 t}\right)}-\left(1+\tau_{t}^{N_{2}}\right) p_{2 t}-\kappa+(1-\rho) E_{t}\left\{\Xi_{t+1 \mid t}\left(\mathbf{M}_{2 t+1}-\mathbf{S}_{t+1}\right)\right\}
$$




\section{D.1.2 Cash Matches}

An individual who is a cash customer (whether a first-time customer or a long-time customer) in period $t$ has value (measured in terms of Walrasian goods) to the household

$$
\mathbf{M}_{1 t}=\frac{\vartheta v_{N_{1}}\left(N_{1 t}, N_{2 t}\right)}{u_{x_{2}}\left(x_{1 t}, x_{2 t}\right)}-p_{1 t} R_{t}\left(1+\tau_{t}^{N_{1}}\right)+(1-\rho) E_{t}\left\{\Xi_{t+1 \mid t} \frac{\mathbf{V}_{N_{1}}\left(N_{1 t+1}, N_{2 t+1}\right)}{u_{x_{2}}\left(x_{1 t}, x_{2 t}\right)}\right\} .
$$

The payoffs are utility net of the bargained payment, which is affected by the nominal interest rate $R$, in addition to the marginal value to the household of entering period $t+1$ with another preexisting cash customer relationship, which is measured by the household-level envelope condition.

The surplus from purchasing via cash at a store is thus

$$
\begin{aligned}
\mathbf{M}_{1 t}-\mathbf{S}_{t} & =\frac{\vartheta v_{N_{1}}\left(N_{1 t}, N_{2 t}\right)}{u_{x_{2}}\left(x_{1 t}, x_{2 t}\right)}-p_{1 t} R_{t}\left(1+\tau_{t}^{N_{1}}\right)-\kappa+(1-\rho) E_{t}\left\{\Xi_{t+1 \mid t} \frac{\mathbf{V}_{N_{1}}\left(N_{1 t+1}, N_{2 t+1}\right)}{u_{x_{2}}\left(x_{1 t}, x_{2 t}\right)}\right\} \\
& =\frac{\vartheta v_{N_{1}}\left(N_{1 t}, N_{2 t}\right)}{u_{x_{2}}\left(x_{1 t}, x_{2 t}\right)}-p_{1 t} R_{t}\left(1+\tau_{t}^{N_{1}}\right)-\kappa+(1-\rho) E_{t}\left\{\Xi_{t+1 \mid t}\left[\frac{\vartheta v_{N_{1}}\left(N_{1 t+1}, N_{2 t+1}\right)}{u_{x_{2}}\left(x_{1 t+1}, x_{2 t+1}\right)}-p_{2 t+1} R_{t+1}\right]\right\} \\
& +(1-\rho) E_{t}\left\{\Xi_{t+1 \mid t}\left[\frac{h^{\prime}\left(l_{t+1}+s_{t+1}\right)}{u_{x_{2}}\left(x_{1 t+1}, x_{2 t+1}\right)} \frac{1}{k_{1 t+1}^{h}}-\left(\frac{1-k_{1 t+1}^{h}}{k_{1 t+1}^{h}}\right) \kappa\right]\right\},
\end{aligned}
$$

in which the second line makes use of the envelope condition (69). Comparing (95) to condition (69), it is clear that

$$
\mathbf{M}_{1 t}-\mathbf{S}_{t}=\frac{h^{\prime}\left(l_{t}+s_{t}\right)}{u_{x_{2}}\left(x_{1 t}, x_{2 t}\right)} \frac{1}{k_{1 t}^{h}}-\left(\frac{1-k_{1 t}^{h}}{k_{1 t}^{h}}\right) \kappa .
$$

The surplus earned by the household of successfully completing a purchase of credit customer goods can finally be expressed as

$$
\mathbf{M}_{1 t}-\mathbf{S}_{t}=\frac{\vartheta v_{N_{1}}\left(N_{1 t}, N_{2 t}\right)}{u_{x_{2}}\left(x_{1 t}, x_{2 t}\right)}-p_{1 t} R_{t}\left(1+\tau_{t}^{N_{1}}\right)-\kappa+(1-\rho) E_{t}\left\{\Xi_{t+1 \mid t}\left(\mathbf{M}_{1 t+1}-\mathbf{S}_{t+1}\right)\right\}
$$

\section{D.2 Value Equations for Customer Market Firms}

Any posted advertisement that does not end up attracting a customer has zero value. The value (denominated in Walrasian goods) to the firm of individuals who are purchasing (whether a firsttime customer or a long-time customer) via cash is

$$
\begin{aligned}
\mathbf{A}_{1 t} & =p_{1 t}-1+(1-\rho) E_{t}\left\{\Xi_{t+1 \mid t} \mathbf{F}_{N_{1}}\left(N_{1 t+1}, N_{2 t+1}\right)\right\} \\
& =p_{1 t}-1+(1-\rho) E_{t}\left\{\Xi_{t+1 \mid t}\left[p_{1 t+1}-1+\frac{\left(1-\tau_{t+1}^{a_{1}}\right) \gamma_{1}}{k_{1 t+1}^{f}}\right]\right\},
\end{aligned}
$$

in which the second line makes use of the envelope condition (87); and the value to the firm of individuals who are purchasing via credit is

$$
\begin{aligned}
\mathbf{A}_{2 t} & =p_{2 t}-1+(1-\rho) E_{t}\left\{\Xi_{t+1 \mid t} \mathbf{F}_{N_{2}}\left(N_{1 t+1}, N_{2 t+1}\right)\right\} \\
& =p_{2 t}-1+(1-\rho) E_{t}\left\{\Xi_{t+1 \mid t}\left[p_{2 t+1}-1+\frac{\left(1-\tau_{t+1}^{a_{2}}\right) \gamma_{2}}{k_{2 t+1}^{f}}\right]\right\},
\end{aligned}
$$


Because unmatched advertisements have zero value, the surplus to the firm is simply $\mathbf{A}_{1 t}$ for cash customers and $\mathbf{A}_{2 t}$ for credit customers. For use in the Nash bargaining problems, note that $\frac{\gamma_{1}\left(1-\tau_{t}^{a_{1}}\right)}{k_{1 t}^{f}}=(1-\rho) E_{t}\left\{\Xi_{t+1 \mid t} \mathbf{A}_{1 t+1}\right\}$ and $\frac{\gamma_{2}\left(1-\tau_{t}^{a_{2}}\right)}{k_{2 t}^{f}}=(1-\rho) E_{t}\left\{\Xi_{t+1 \mid t} \mathbf{A}_{2 t+1}\right\}$, which can be seen from the firm analysis above.

\section{D.3 Nash Bargaining}

The firm bargains individually with each of its customers, whether a new customer, a long-time customer, a cash customer, or a credit customer, in every period. For every customer, the firm and the shopper choose the price that maximizes the generalized Nash product

$$
\left(\mathbf{M}_{i t}-\mathbf{S}_{t}\right)^{\eta_{i}} \mathbf{A}_{i t}^{1-\eta_{i}}
$$

in which $\eta_{i} \in(0,1)$ measures the bargaining power of the customer and $i \in\{1,2\}$ denotes cash customers or credit customers.

The first-order condition of (100) with respect to the period-t price is

$$
\eta_{i}\left(\mathbf{M}_{i t}-\mathbf{S}_{t}\right)^{\eta_{i}-1} \mathbf{A}_{i t}^{1-\eta_{i}}\left(\frac{\partial \mathbf{M}_{i t}}{\partial p_{i t}}-\frac{\partial \mathbf{S}_{t}}{\partial p_{i t}}\right)+\left(1-\eta_{i}\right)\left(\mathbf{M}_{i t}-\mathbf{S}_{t}\right)^{\eta_{i}} \mathbf{A}_{i t}^{-\eta_{i}} \frac{\partial \mathbf{A}_{i t}}{\partial p_{i t}}=0 .
$$

To simplify, multiply by $\mathbf{A}_{i t}^{\eta_{i}}$, and also multiply by $\left(\mathbf{M}_{i t}-\mathbf{S}_{t}\right)^{1-\eta_{i}}$, which gives

$$
\eta_{i} \mathbf{A}_{i t}\left(\frac{\partial \mathbf{M}_{i t}}{\partial p_{i t}}-\frac{\partial \mathbf{S}_{\mathbf{t}}}{\partial p_{i t}}\right)+\left(1-\eta_{i}\right)\left(\mathbf{M}_{i t}-\mathbf{S}_{t}\right) \frac{\partial \mathbf{A}_{i t}}{\partial p_{i t}}=0
$$

It is clear from the value equations above that the marginals are $\frac{\partial \mathbf{A}_{i t}}{\partial p_{i t}}=1, \frac{\partial \mathbf{S}_{t}}{\partial p_{i t}}=0$, and $\frac{\partial \mathbf{M}_{1 t}}{\partial p_{1 t}}=-R_{t}\left(1+\tau_{t}^{N_{1}}\right)$ and $\frac{\partial \mathbf{M}_{2 t}}{\partial p_{2 t}}=-\left(1+\tau_{t}^{N_{2}}\right)$.

Substituting these, the first-order condition for cash-good bargaining simplifies to

$$
\frac{\mathbf{M}_{1 t}-\mathbf{S}_{t}}{R_{t}\left(1+\tau_{t}^{N_{1}}\right)}=\frac{\eta_{1}}{1-\eta_{1}} \mathbf{A}_{1 t}
$$

and for credit-good bargaining to

$$
\frac{\mathbf{M}_{2 t}-\mathbf{S}_{t}}{1+\tau_{t}^{N_{2}}}=\frac{\eta_{2}}{1-\eta_{2}} \mathbf{A}_{2 t},
$$

which is the usual Nash sharing rule, here with either the nominal interest rate - expression (103) — or proportional taxes - expression (104) — on relationship goods taken into consideration when prices are determined.

Now proceed to derive explicit expressions for $p_{1 t}$ and $p_{2 t}$. 


\section{D.3.1 Nash Cash Pricing}

Inserting the expression for $\mathbf{M}_{1 t}-\mathbf{S}_{t}$ into the Nash sharing rule (103),

$$
\frac{\frac{\vartheta v_{N_{1}}\left(N_{1 t}, N_{2 t}\right)}{u_{x_{2}}\left(x_{1 t}, x_{2 t}\right)}-p_{1 t} R_{t}\left(1+\tau_{t}^{N_{1}}\right)-\kappa+(1-\rho) E_{t}\left\{\Xi_{t+1 \mid t}\left(\mathbf{M}_{1 t+1}-\mathbf{S}_{t+1}\right)\right\}}{R_{t}}=\frac{\eta_{1}}{1-\eta_{1}} \mathbf{A}_{1 t}
$$

rewriting this slightly,

$$
\left(\frac{\vartheta v_{N_{1}}\left(N_{1 t}, N_{2 t}\right) / u_{x_{2}}\left(x_{1 t}, x_{2 t}\right)-\kappa}{R_{t}\left(1+\tau_{t}^{N_{1}}\right)}\right)-p_{1 t}+\frac{1-\rho}{R_{t}\left(1+\tau_{t}^{N_{1}}\right)} E_{t}\left\{\Xi_{t+1 \mid t}\left(\mathbf{M}_{1 t+1}-\mathbf{S}_{t+1}\right)\right\}=\frac{\eta_{1}}{1-\eta_{1}} \mathbf{A}_{1 t} .
$$

Next, use the time- $t+1$ Nash sharing rule to get

$\left(\frac{\vartheta v_{N_{1}}\left(N_{1 t}, N_{2 t}\right) / u_{x_{2}}\left(x_{1 t}, x_{2 t}\right)-\kappa}{R_{t}\left(1+\tau_{t}^{N_{1}}\right)}\right)-p_{1 t}+\frac{1-\rho}{R_{t}\left(1+\tau_{t}^{N_{1}}\right)} E_{t}\left\{\Xi_{t+1 \mid t} R_{t+1}\left(1+\tau_{t+1}^{N_{1}}\right) \frac{\eta_{1}}{1-\eta_{1}} \mathbf{A}_{1 t+1}\right\}=\frac{\eta_{1}}{1-\eta_{1}} \mathbf{A}_{1 t}$.

Make the substitution $\mathbf{A}_{1 t}=p_{1 t}-1+\frac{\gamma_{1}\left(1-\tau_{t}^{a_{1}}\right)}{k_{1 t}^{f}}$, which yields

$$
\begin{aligned}
& \left(\frac{\vartheta v_{N_{1}}\left(N_{1 t}, N_{2 t}\right) / u_{x_{2}}\left(x_{1 t}, x_{2 t}\right)-\kappa}{R_{t}\left(1+\tau_{t}^{N_{1}}\right)}\right)-p_{1 t} \\
& \quad+\frac{1-\rho}{R_{t}\left(1+\tau_{t}^{N_{1}}\right)} E_{t}\left\{\Xi_{t+1 \mid t} R_{t+1}\left(1+\tau_{t+1}^{N_{1}}\right) \frac{\eta_{1}}{1-\eta_{1}} \mathbf{A}_{1 t+1}\right\}=\frac{\eta_{1}}{1-\eta_{1}}\left[p_{1 t}-1+\frac{\gamma_{1}\left(1-\tau_{t}^{a_{1}}\right)}{k_{1 t}^{f}}\right]
\end{aligned}
$$

Next, use the condition $\frac{\gamma_{1}\left(1-\tau_{t}^{a_{1}}\right)}{k_{1 t}^{f}}=(1-\rho) E_{t}\left\{\Xi_{t+1 \mid t} \mathbf{A}_{1 t+1}\right\}$ to substitute on the right-hand-side, which gives

$$
\begin{aligned}
& \left(\frac{\vartheta v_{N_{1}}\left(N_{1 t}, N_{2 t}\right) / u_{x_{2}}\left(x_{1 t}, x_{2 t}\right)-\kappa}{R_{t}\left(1+\tau_{t}^{N_{1}}\right)}\right)-p_{1 t} \\
& +\frac{1-\rho}{R_{t}\left(1+\tau_{t}^{N_{1}}\right)} E_{t}\left\{\Xi_{t+1 \mid t} R_{t+1}\left(1+\tau_{t+1}^{N_{1}}\right) \frac{\eta_{1}}{1-\eta_{1}} \mathbf{A}_{1 t+1}\right\} \\
& =\frac{\eta_{1}}{1-\eta_{1}}\left(p_{1 t}-1\right)+\frac{\eta_{1}}{1-\eta_{1}}(1-\rho) E_{t}\left\{\Xi_{t+1 \mid t} \mathbf{A}_{1 t+1}\right\}
\end{aligned}
$$

Grouping terms involving $\mathbf{A}_{1 t+1}$,

$$
\begin{aligned}
& \left(\frac{\vartheta v_{N_{1}}\left(N_{1 t}, N_{2 t}\right) / u_{x_{2}}\left(x_{1 t}, x_{2 t}\right)-\kappa}{R_{t}\left(1+\tau_{t}^{N_{1}}\right)}\right)-p_{1 t} \\
& \quad+\frac{\eta_{1}}{1-\eta_{1}}(1-\rho) E_{t}\left\{\Xi_{t+1 \mid t}\left[\frac{R_{t+1}\left(1+\tau_{t+1}^{N_{1}}\right)}{R_{t}\left(1+\tau_{t}^{N_{1}}\right)}-1\right] \mathbf{A}_{1 t+1}\right\} \\
& \quad=\frac{\eta_{1}}{1-\eta_{1}}\left(p_{1 t}-1\right)
\end{aligned}
$$

Next, grouping terms involving $p_{1 t}$,

$$
\begin{aligned}
& p_{1 t}\left[\frac{\eta_{1}}{1-\eta_{1}}+1\right]=\left(\frac{\vartheta v_{N_{1}}\left(N_{1 t}, N_{2 t}\right) / u_{x_{2}}\left(x_{1 t}, x_{2 t}\right)-\kappa}{R_{t}\left(1+\tau_{t}^{N_{1}}\right)}\right)+\frac{\eta_{1}}{1-\eta_{1}} \\
& +\frac{\eta_{1}}{1-\eta_{1}}(1-\rho) E_{t}\left\{\Xi_{t+1 \mid t}\left[\frac{R_{t+1}\left(1+\tau_{t+1}^{N_{1}}\right)}{R_{t}\left(1+\tau_{t}^{N_{1}}\right)}-1\right] \mathbf{A}_{1 t+1}\right\} .
\end{aligned}
$$


Multiplying by $\left(1-\eta_{1}\right)$,

$$
\begin{gathered}
p_{1 t}=\left(1-\eta_{1}\right)\left(\frac{\vartheta v_{N_{1}}\left(N_{1 t}, N_{2 t}\right) / u_{x_{2}}\left(x_{1 t}, x_{2 t}\right)-\kappa}{R_{t}\left(1+\tau_{t}^{N_{1}}\right)}\right)+\eta_{1} \\
+\eta_{1}(1-\rho) E_{t}\left\{\Xi_{t+1 \mid t}\left[\frac{R_{t+1}\left(1+\tau_{t+1}^{N_{1}}\right)}{R_{t}\left(1+\tau_{t}^{N_{1}}\right)}-1\right] \mathbf{A}_{1 t+1}\right\} .
\end{gathered}
$$

Separating the terms inside the $E_{t}$ operator

$$
\begin{aligned}
p_{1 t} & =\left(1-\eta_{1}\right)\left(\frac{\vartheta v_{N_{1}}\left(N_{1 t}, N_{2 t}\right) / u_{x_{2}}\left(x_{1 t}, x_{2 t}\right)-\kappa}{R_{t}\left(1+\tau_{t}^{N_{1}}\right)}\right)+\eta_{1} \\
& +\eta_{1}(1-\rho) E_{t}\left\{\Xi_{t+1 \mid t}\left(\frac{R_{t+1}\left(1+\tau_{t+1}^{N_{1}}\right)}{R_{t}\left(1+\tau_{t}^{N_{1}}\right)}\right) \mathbf{A}_{1 t+1}\right\}-\eta_{1}(1-\rho) E_{t}\left\{\Xi_{t+1 \mid t} \mathbf{A}_{1 t+1}\right\} .
\end{aligned}
$$

Then, because $\frac{\gamma_{1}\left(1-\tau_{t}^{a_{1}}\right)}{k_{1 t}^{f}}=(1-\rho) E_{t}\left\{\Xi_{t+1 \mid t} \mathbf{A}_{1 t+1}\right\}$, rewrite as

$$
\begin{aligned}
p_{1 t} & =\left(1-\eta_{1}\right)\left(\frac{\vartheta v_{N_{1}}\left(N_{1 t}, N_{2 t}\right) / u_{x_{2}}\left(x_{1 t}, x_{2 t}\right)-\kappa}{R_{t}\left(1+\tau_{t}^{N_{1}}\right)}\right)+\eta_{1} \\
& +\eta_{1}(1-\rho) E_{t}\left\{\Xi_{t+1 \mid t}\left(\frac{R_{t+1}\left(1+\tau_{t+1}^{N_{1}}\right)}{R_{t}\left(1+\tau_{t}^{N_{1}}\right)}\right) \mathbf{A}_{1 t+1}\right\}-\eta_{1} \frac{\gamma_{1}\left(1-\tau_{t}^{a_{1}}\right)}{k_{1 t}^{f}}
\end{aligned}
$$




\section{D.3.2 Nash Credit Pricing}

Inserting the expression for $\mathbf{M}_{2 t}-\mathbf{S}_{t}$ into the Nash sharing rule (104),

$$
\frac{\frac{\vartheta v_{N_{2}}\left(N_{1 t}, N_{2 t}\right)}{u_{x_{2}}\left(x_{1 t}, x_{2 t}\right)}-\left(1+\tau_{t}^{N_{2}}\right) p_{2 t}-\kappa+(1-\rho) E_{t}\left\{\Xi_{t+1 \mid t}\left(\mathbf{M}_{2 t+1}-\mathbf{S}_{t+1}\right)\right\}}{1+\tau_{t}^{N_{2}}}=\frac{\eta_{2}}{1-\eta_{2}} \mathbf{A}_{2 t}
$$

rewriting this slightly,

$$
\left(\frac{\vartheta v_{N_{2}}\left(N_{1 t}, N_{2 t}\right) / u_{x_{2}}\left(x_{1 t}, x_{2 t}\right)-\kappa}{1+\tau_{t}^{N_{2}}}\right)-p_{2 t}+\frac{1-\rho}{1+\tau_{t}^{N_{2}}} E_{t}\left\{\Xi_{t+1 \mid t}\left(\mathbf{M}_{2 t+1}-\mathbf{S}_{t+1}\right)\right\}=\frac{\eta_{2}}{1-\eta_{2}} \mathbf{A}_{2 t} .
$$

Next, use the time- $t+1$ Nash sharing rule to get

$$
\left(\frac{\vartheta v_{N_{2}}\left(N_{1 t}, N_{2 t}\right) / u_{x_{2}}\left(x_{1 t}, x_{2 t}\right)-\kappa}{1+\tau_{t}^{N_{2}}}\right)-p_{2 t}+\frac{1-\rho}{1+\tau_{t}^{N_{2}}} E_{t}\left\{\Xi_{t+1 \mid t}\left(1+\tau_{t+1}^{N_{2}}\right) \frac{\eta_{2}}{1-\eta_{2}} \mathbf{A}_{2 t+1}\right\}=\frac{\eta_{2}}{1-\eta_{2}} \mathbf{A}_{2 t} .
$$

Make the substitution $\mathbf{A}_{2 t}=p_{2 t}-1+\frac{\gamma_{2}\left(1-\tau_{t}^{a_{2}}\right)}{k_{2 t}^{f}}$, which yields

$$
\begin{aligned}
& \left(\frac{\vartheta v_{N_{2}}\left(N_{1 t}, N_{2 t}\right) / u_{x_{2}}\left(x_{1 t}, x_{2 t}\right)-\kappa}{1+\tau_{t}^{N_{2}}}\right)-p_{2 t} \\
& \quad+\frac{1-\rho}{R_{t}\left(1+\tau_{t}^{N_{1}}\right)} E_{t}\left\{\Xi_{t+1 \mid t}\left(1+\tau_{t+1}^{N_{2}}\right) \frac{\eta_{2}}{1-\eta_{2}} \mathbf{A}_{2 t+1}\right\}=\frac{\eta_{2}}{1-\eta_{2}}\left[p_{2 t}-1+\frac{\gamma_{2}\left(1-\tau_{t}^{a_{2}}\right)}{k_{2 t}^{f}}\right]
\end{aligned}
$$

Next, use the condition $\frac{\gamma_{2}\left(1-\tau_{t}^{a_{2}}\right)}{k_{2 t}^{f}}=(1-\rho) E_{t}\left\{\Xi_{t+1 \mid t} \mathbf{A}_{2 t+1}\right\}$ to substitute on the right-hand-side, which gives

$$
\begin{aligned}
& \left(\frac{\vartheta v_{N_{2}}\left(N_{1 t}, N_{2 t}\right) / u_{x_{2}}\left(x_{1 t}, x_{2 t}\right)-\kappa}{1+\tau_{t}^{N_{2}}}\right)-p_{2 t} \\
& \quad+\frac{1-\rho}{1+\tau_{t}^{N_{2}}} E_{t}\left\{\Xi_{t+1 \mid t}\left(1+\tau_{t+1}^{N_{2}}\right) \frac{\eta_{2}}{1-\eta_{2}} \mathbf{A}_{2 t+1}\right\} \\
& \quad=\frac{\eta_{2}}{1-\eta_{2}}\left(p_{2 t}-1\right)+\frac{\eta_{2}}{1-\eta_{2}}(1-\rho) E_{t}\left\{\Xi_{t+1 \mid t} \mathbf{A}_{2 t+1}\right\}
\end{aligned}
$$

Grouping terms involving $\mathbf{A}_{2 t+1}$,

$$
\begin{aligned}
& \left(\frac{\vartheta v_{N_{2}}\left(N_{1 t}, N_{2 t}\right) / u_{x_{2}}\left(x_{1 t}, x_{2 t}\right)-\kappa}{1+\tau_{t}^{N_{2}}}\right)-p_{2 t} \\
& +\frac{\eta_{2}}{1-\eta_{2}}(1-\rho) E_{t}\left\{\Xi_{t+1 \mid t}\left[\frac{1+\tau_{t+1}^{N_{2}}}{1+\tau_{t}^{N_{2}}}-1\right] \mathbf{A}_{2 t+1}\right\} \\
& =\frac{\eta_{2}}{1-\eta_{2}}\left(p_{2 t}-1\right) .
\end{aligned}
$$

Next, grouping terms involving $p_{2 t}$,

$$
\begin{aligned}
& p_{2 t}\left[\frac{\eta_{2}}{1-\eta_{2}}+1\right]=\left(\frac{\vartheta v_{N_{2}}\left(N_{1 t}, N_{2 t}\right) / u_{x_{2}}\left(x_{1 t}, x_{2 t}\right)-\kappa}{1+\tau_{t}^{N_{2}}}\right)+\frac{\eta_{2}}{1-\eta_{2}} \\
& \quad+\frac{\eta_{2}}{1-\eta_{2}}(1-\rho) E_{t}\left\{\Xi_{t+1 \mid t}\left[\frac{1+\tau_{t+1}^{N_{2}}}{1+\tau_{t}^{N_{2}}}-1\right] \mathbf{A}_{2 t+1}\right\} .
\end{aligned}
$$


Multiplying by $\left(1-\eta_{2}\right)$,

$$
\begin{aligned}
p_{2 t} & =\left(1-\eta_{2}\right)\left(\frac{\vartheta v_{N_{2}}\left(N_{1 t}, N_{2 t}\right) / u_{x_{2}}\left(x_{1 t}, x_{2 t}\right)-\kappa}{1+\tau_{t}^{N_{2}}}\right)+\eta_{2} \\
& +\eta_{2}(1-\rho) E_{t}\left\{\Xi_{t+1 \mid t}\left[\frac{1+\tau_{t+1}^{N_{2}}}{1+\tau_{t}^{N_{2}}}-1\right] \mathbf{A}_{2 t+1}\right\} .
\end{aligned}
$$

Separating the terms inside the $E_{t}$ operator

$$
\begin{aligned}
p_{2 t} & =\left(1-\eta_{2}\right)\left(\frac{\vartheta v_{N_{2}}\left(N_{1 t}, N_{2 t}\right) / u_{x_{2}}\left(x_{1 t}, x_{2 t}\right)-\kappa}{1+\tau_{t}^{N_{2}}}\right)+\eta_{2} \\
& +\eta_{2}(1-\rho) E_{t}\left\{\Xi_{t+1 \mid t}\left(\frac{1+\tau_{t+1}^{N_{2}}}{1+\tau_{t}^{N_{2}}}\right) \mathbf{A}_{2 t+1}\right\}-\eta_{2}(1-\rho) E_{t}\left\{\Xi_{t+1 \mid t} \mathbf{A}_{2 t+1}\right\} .
\end{aligned}
$$

Then, because $\frac{\gamma_{2}\left(1-\tau_{t}^{a_{2}}\right)}{k_{2 t}^{f}}=(1-\rho) E_{t}\left\{\Xi_{t+1 \mid t} \mathbf{A}_{2 t+1}\right\}$, rewrite as

$$
\begin{aligned}
p_{2 t} & =\left(1-\eta_{2}\right)\left(\frac{\vartheta v_{N_{2}}\left(N_{1 t}, N_{2 t}\right) / u_{x_{2}}\left(x_{1 t}, x_{2 t}\right)-\kappa}{1+\tau_{t}^{N_{2}}}\right)+\eta_{2} \\
& +\eta_{2}(1-\rho) E_{t}\left\{\Xi_{t+1 \mid t}\left(\frac{1+\tau_{t+1}^{N_{2}}}{1+\tau_{t}^{N_{2}}}\right) \mathbf{A}_{2 t+1}\right\}-\eta_{2} \frac{\gamma_{2}\left(1-\tau_{t}^{a_{2}}\right)}{k_{2 t}^{f}} .
\end{aligned}
$$




\section{E Definition of Equilibrium}

Decentralized bargaining equilibrium are state-contingent functions for $\left\{x_{1 t}, x_{2 t}, l_{t}, a_{1 t}, s_{1 t}, a_{2 t}, s_{2 t}, N_{1 t+1}, N_{2 t+1}, w_{t}, m c_{t}, p_{1 t}, p_{2 t}, R_{t}, \pi_{t}, \mathbf{A}_{1 t}, \mathbf{A}_{2 t},\right\}$ that satisfy: the consumptionlabor optimality condition

$$
\frac{h^{\prime}\left(l_{t}+s_{t}\right)}{u_{x_{2}}\left(x_{1 t}, x_{2 t}\right)}=\left(1-\tau_{t}^{l}\right)\left(1+\tau_{t}^{w}\right) w_{t},
$$

the (Walrasian) cash-good/credit-good optimality condition

$$
\frac{u_{x_{1}}\left(x_{1 t}, x_{2 t}\right)}{u_{x_{2}}\left(x_{1 t}, x_{2 t}\right)}=R_{t},
$$

the binding CIA constraint (stated in real terms)

$$
\frac{x_{1 t}+\left(1+\tau_{t}^{N_{1}}\right) p_{1 t} N_{1 t}}{x_{1 t-1}+\left(1+\tau_{t-1}^{N_{1}}\right) p_{1 t-1} N_{1 t-1}}=\frac{\mu_{t}}{\pi_{t}}
$$

the pricing condition for the one-period nominally risk-free government bond

$$
1=R_{t} E_{t}\left[\frac{\beta u_{x_{1}}\left(x_{1 t+1}, x_{2 t+1}\right)}{u_{x_{1}}\left(x_{1 t}, x_{2 t}\right)} \frac{1}{\pi_{t+1}}\right],
$$

the optimal shopping condition for cash goods

$$
\begin{aligned}
& \frac{h^{\prime}\left(l_{t}+s_{t}\right)}{u_{x_{2}}\left(x_{1 t}, x_{2 t}\right)}=\left(1-k_{1 t}^{h}\right) \kappa \\
& \quad+\quad k_{1 t}^{h}(1-\rho) E_{t}\left\{\Xi_{t+1 \mid t}\left[\frac{\vartheta v_{N_{1}}\left(N_{1 t+1}, N_{2 t+1}\right)}{u_{x_{2}}\left(x_{1 t+1}, x_{2 t+1}\right)}-p_{1 t+1} R_{t+1}\left(1+\tau_{t+1}^{N_{1}}\right)+\frac{h^{\prime}\left(l_{t+1}+s_{t+1}\right)}{u_{x_{2}}\left(x_{1 t+1}, x_{2 t+1}\right)} \frac{1}{k_{1 t+1}^{h}}-\left(\frac{1-k_{1 t+1}^{h}}{k_{1 t+1}^{h}}\right) \kappa\right]\right.
\end{aligned}
$$

the optimal shopping condition for credit goods

$$
\begin{aligned}
& \frac{h^{\prime}\left(l_{t}+s_{t}\right)}{u_{x_{2}}\left(x_{1 t}, x_{2 t}\right)}=\left(1-k_{2 t}^{h}\right) \kappa \\
& \quad+\quad k_{2 t}^{h}(1-\rho) E_{t}\left\{\Xi_{t+1 \mid t}\left[\frac{\vartheta v_{N_{2}}\left(N_{1 t+1}, N_{2 t+1}\right)}{u_{x_{2}}\left(x_{1 t+1}, x_{2 t+1}\right)}-\left(1+\tau_{t+1}^{N_{2}}\right) p_{2 t+1}+\frac{h^{\prime}\left(l_{t+1}+s_{t+1}\right)}{u_{x_{2}}\left(x_{1 t+1}, x_{2 t+1}\right)} \frac{1}{k_{2 t+1}^{h}}-\left(\frac{1-k_{2 t+1}^{h}}{k_{2 t+1}^{h}}\right) \kappa\right]\right\},
\end{aligned}
$$

the optimal advertising condition for cash goods

$$
\frac{\left(1-\tau_{t}^{a_{1}}\right) \gamma_{1}}{k_{1 t}^{f}}=(1-\rho) E_{t}\left\{\Xi_{t+1 \mid t}\left(p_{1 t+1}-1+\frac{\left(1-\tau_{t+1}^{a_{1}}\right) \gamma_{1}}{k_{1 t+1}^{f}}\right)\right\},
$$

the optimal advertising condition for credit goods

$$
\frac{\left(1-\tau_{t}^{a_{2}}\right) \gamma_{2}}{k_{2 t}^{f}}=(1-\rho) E_{t}\left\{\Xi_{t+1 \mid t}\left(p_{2 t+1}-1+\frac{\left(1-\tau_{t+1}^{a_{2}}\right) \gamma_{2}}{k_{2 t+1}^{f}}\right)\right\},
$$


the Nash pricing condition for cash customer goods

$$
\begin{aligned}
p_{1 t} & =\left(1-\eta_{1}\right)\left(\frac{\vartheta v_{N_{1}}\left(N_{1 t}, N_{2 t}\right) / u_{x_{2}}\left(x_{1 t}, x_{2 t}\right)-\kappa}{R_{t}\left(1+\tau_{t}^{N_{1}}\right)}\right)+\eta_{1} \\
+ & \eta_{1}(1-\rho) E_{t}\left\{\Xi_{t+1 \mid t}\left[\frac{R_{t+1}\left(1+\tau_{t+1}^{N_{1}}\right)}{R_{t}\left(1+\tau_{t}^{N_{1}}\right)}-1\right] \mathbf{A}_{1 t+1}\right\},
\end{aligned}
$$

the Nash pricing condition for credit customer goods

$$
\begin{aligned}
& p_{2 t}=\left(1-\eta_{2}\right)\left(\frac{\vartheta v_{N_{2}}\left(N_{1 t}, N_{2 t}\right) / u_{x_{2}}\left(x_{1 t}, x_{2 t}\right)-\kappa}{1+\tau_{t}^{N_{2}}}\right)+\eta_{2} \\
& \quad+\eta_{2}(1-\rho) E_{t}\left\{\Xi_{t+1 \mid t}\left[\frac{1+\tau_{t+1}^{N_{2}}}{1+\tau_{t}^{N_{2}}}-1\right] \mathbf{A}_{2 t+1}\right\},
\end{aligned}
$$

, the value to a firm of individuals who are purchasing via cash

$$
\mathbf{A}_{1 t}=p_{1 t}-1+(1-\rho) E_{t}\left\{\Xi_{t+1 \mid t}\left[p_{1 t+1}-1+\frac{\left(1-\tau_{t+1}^{a_{1}}\right) \gamma_{1}}{k_{1 t+1}^{f}}\right]\right\},
$$

the value to a firm of individuals who are purchasing via credit

$$
\mathbf{A}_{2 t}=p_{2 t}-1+(1-\rho) E_{t}\left\{\Xi_{t+1 \mid t}\left[p_{2 t+1}-1+\frac{\left(1-\tau_{t+1}^{a_{2}}\right) \gamma_{2}}{k_{2 t+1}^{f}}\right]\right\},
$$

the aggregate law of motion for cash customer relationships

$$
N_{1 t+1}=(1-\rho)\left(N_{1 t}+m\left(s_{1 t}, a_{1 t}\right)\right)
$$

the aggregate law of motion for credit customer relationships

$$
N_{2 t+1}=(1-\rho)\left(N_{2 t}+m\left(s_{2 t}, a_{2 t}\right)\right)
$$

the New Keynesian Phillips Curve

$$
0=\left(1-\varepsilon+\varepsilon m c_{t}\right) z_{t} l_{t}-\varphi\left(\pi_{t}-\pi^{*}\right) \pi_{t}+E_{t} \Xi_{t+1 \mid t} \varphi\left(\pi_{t+1}-\pi^{*}\right) \pi_{t+1},
$$

with marginal cost defined as

$$
m c_{t}=\frac{w_{t}}{z_{t}}
$$

and the aggregate goods resource constraint

$$
x_{1 t-1}+x_{2 t-1}+N_{1 t-1}+N_{2 t-1}+g_{t-1}+\gamma_{1} a_{1 t-1}+\gamma_{2} a_{2 t-1}+\frac{\varphi}{2}\left(\pi_{t-1}-\pi^{*}\right)=z_{t-1} l_{t-1}
$$

for given exogenous processes $\left\{z_{t}, g_{t}, \tau_{t}^{l}, \mu_{t}, \tau_{t}^{N_{1}}, \tau_{t}^{N_{2}}, \tau_{t}^{a_{1}}, \tau_{t}^{a_{2}}, \tau_{t}^{w}\right\}$. The resource constraint is stated in period $t-1$ terms because of the timing of markets in the model - specifically, because (all) goods are paid for with a one period lag, summing the time- $t$ consumer and government budget constraints gives rise to the time- $(t-1)$ goods resource constraint. ${ }^{20}$

\footnotetext{
${ }^{20}$ This specification is exactly the same as in Lucas and Stokey (1983) and Chari and Kehoe (1999). We note a technical issue this timing imposes on the formulation of the Ramsey problem below.
} 


\section{F Details of Estimation}

\section{F.1 Computing Steady-State}

Analytically computing the steady-state of the model is a non-trivial task. Here we summarize the steps we take. Define $\Psi=\frac{\beta(1-\rho)}{1-\beta(1-\rho)}$. Then, with a few simplifications, the stationary first-order conditions of the model are

$$
\begin{aligned}
\frac{\zeta(l+s)^{\frac{1}{\nu}}}{u_{x_{2}}} & =\left(1-\tau^{l}\right) w \\
R & =\frac{1-\kappa_{x}}{\kappa_{x}}\left(\frac{x_{1}}{x_{2}}\right)^{\phi_{x}-1} \\
\mu & =\pi^{*}\left(x_{1}+\left(1+\tau^{N}\right) p_{1} N_{1}\right) \\
R & =\frac{\pi^{*}}{\beta} \\
\left(1-\tau^{l}\right) w & =\left(1-k_{1}^{h}\right) \kappa+k_{1}^{h} \Psi\left[\frac{\vartheta v_{N_{1}}}{u_{x_{2}}}-p_{1} R\left(1+\tau^{N_{1}}\right)\right] \\
\left(1-\tau^{l}\right) w & =\left(1-k_{2}^{h}\right) \kappa+k_{2}^{h} \Psi\left[\frac{\vartheta v_{N_{2}}}{u_{x_{2}}}-p_{2}\left(1+\tau^{N_{2}}\right)\right] \\
\left(1-\tau^{a_{1}}\right) \gamma_{1} & =k_{1}^{f} \Psi\left(p_{1}-1\right) \\
\left(1-\tau^{a_{2}}\right) \gamma_{2} & =k_{2}^{f} \Psi\left(p_{2}-1\right) \\
p_{1} & =\left(1-\eta_{1}\right)\left(\frac{\vartheta v_{N_{1}} / u_{x_{2}}-\kappa}{R\left(1+\tau^{N_{1}}\right)}\right)+\eta_{1} \\
p_{2} & =\left(1-\eta_{2}\right)\left(\frac{\vartheta v_{N_{2}} / u_{x_{2}}-\kappa}{1+\tau^{N_{2}}}\right)+\eta_{2} \\
N_{1} & =\frac{1-\rho}{\rho} a_{1} k_{1}^{f} \\
N_{2} & =\frac{1-\rho}{\rho} a_{2} k_{2}^{f} \\
w & =\frac{\varepsilon-1}{\varepsilon\left(1-\tau^{w}\right)} \\
l & x_{1}+x_{2}+N_{1}+N_{2}+g+\gamma_{1} a_{1}+\gamma_{2} a_{2}
\end{aligned}
$$

To compute the steady state, we fix the steady-state output shares $\Phi_{g}, \Phi_{N_{1}}=\frac{N_{1}}{l}, \Phi_{N_{2}}=\frac{N_{2}}{l}$, $\Phi_{a_{1}}=\frac{\gamma_{1} a_{1}}{l}, \Phi_{a_{2}}=\frac{\gamma_{2} a_{2}}{1}$. The residual share is government spending $\Phi_{x}=\frac{x_{1}+x_{2}}{l}$. We also fix $k_{1}^{f}, k_{2}^{f}$, and impose an arbitrary normalization on steady-state hours. Combined, these eight restrictions pin down the fundamental parameters $\psi_{1}, \psi_{2}, \gamma_{1}, \gamma_{2}, \kappa_{c}, \vartheta, \zeta, g$.

Note that combining shares with the normalization for $l$ immediately gives quantities for $n_{1}, n_{2}, \gamma_{1} a_{1}$, and $\gamma_{2} a_{2}$. Combine equations (148) and (152) to get

$$
p_{1}=1+\frac{\left(1-\tau^{a_{1}}\right) \gamma_{1} a_{1}}{\Psi} \frac{1-\rho}{\rho N_{1}} .
$$


Similarly, combining (149) and (153) yields

$$
p_{2}=1+\frac{\left(1-\tau^{a_{2}}\right) \gamma_{2} a_{2}}{\Psi} \frac{1-\rho}{\rho N_{2}} .
$$

Plugging the expression for $p_{1}$ back into the (148) yields the result

$$
\gamma_{1}=\frac{\Psi(p 1-1) k_{1}^{f}}{1-\tau^{a_{1}}}
$$

Similarly,

$$
\gamma_{2}=\frac{\Psi(p 2-1) k_{2}^{f}}{1-\tau^{a_{2}}} .
$$

From here, the quantities for $a_{1}, a_{2}, s 1, s_{2}, \theta_{1}, \theta_{2}$ follow directly.

Now use equation (150) to solve for

$$
\frac{\vartheta v_{N_{1}}}{u_{X_{2}}}=\frac{p_{1}-\eta_{1}}{1-\eta_{1}} R\left(1+\tau^{N_{1}}\right)+\kappa .
$$

The corresponding expression for equation (151) is

$$
\frac{\vartheta v_{N_{2}}}{u_{X_{2}}}=\frac{p_{2}-\eta_{2}}{1-\eta_{2}}\left(1+\tau^{N_{2}}\right)+\kappa
$$

Combining equations (156), (160), and the steady-state shopping condition in (146) and rearranging yields expressions for $k_{1}^{h}$ and $k_{2}^{h}$

$$
\begin{aligned}
k_{1}^{h} & =\frac{\left(1-\tau_{l}\right) w-\kappa}{\Psi R\left(p_{1}-1\right)\left(1+\tau^{N_{1}}\right) \frac{\eta_{1}}{1-\eta_{1}}+(1-\Psi) \kappa} \\
k_{2}^{h} & =\frac{\left(1-\tau_{l}\right) w-\kappa}{\Psi\left(p_{2}-1\right)\left(1+\tau^{N_{2}}\right) \frac{\eta_{2}}{1-\eta_{2}}+(1-\Psi) \kappa} .
\end{aligned}
$$

From here, equation (143) can be used to back out the quantities of Walrasian goods,

$$
x_{2}=\Phi_{x} l \frac{\left(1-\kappa_{x}\right)^{\frac{1}{\phi_{x}-1}}}{\left(\kappa_{x} R\right)^{\frac{1}{\phi_{x}-1}}+\left(1-\kappa_{x}\right)^{\frac{1}{\phi_{x}-1}}},
$$

and $x_{1}=\Phi_{x} l-x_{2}$.

To solve for $\kappa_{c}$, compute the ratio $\frac{v_{N_{1}}}{v_{N_{2}}}$ using equations (160) and (161). It follows from the function form of $v(\cdot)$ that

$$
\kappa_{c}=\left(\frac{v_{N_{1}}}{v_{N_{2}}}{\frac{N}{N_{2}}}^{\left(1-\phi_{c}\right)}+1\right)^{-1} .
$$

Evaluating the derivative $v_{N_{2}}$, equation (160) yields an expression for $\vartheta$,

$$
\vartheta=\frac{u_{x_{2}}}{v_{N_{1}}}\left(\frac{p_{1}-\eta_{1}}{1-\eta_{1}} R\left(1+\tau^{N_{1}}\right)+\kappa\right) .
$$

Finally, solve equation (142) to derive the implied value of $\zeta$,

$$
\zeta=\left(1-\tau^{l}\right) w u_{x_{2}}(l+s)^{-\frac{1}{\nu}}
$$




\section{F.2 Estimation}

We can summarize the calibration of the exogenous-policy version of the model with the vector of parameters, $\Psi=\left\{\Psi_{1}, \Psi_{2}\right\}$, where

$$
\begin{aligned}
& \Psi_{1}=\left\{\beta, \pi^{*}, \phi_{x}, \phi_{x}, \kappa_{x}, \nu, \varepsilon,, \xi, \Phi_{g}, \Phi_{N_{1}}, \Phi_{N_{2}}, \Phi_{a_{1}}, \Phi_{a_{2}}, k_{1}^{f}, k_{2}^{f}, \bar{l}\right\} \\
& \Psi_{2}=\left\{\varphi, \rho, \kappa, \eta_{1}, \eta_{2}, \sigma_{x}, \sigma_{c}, \sigma_{r}, \sigma_{z}, \sigma_{g}, \sigma_{\tau^{l}}, \rho_{r}, \rho_{z}, \rho_{g}, \rho_{\tau^{l}}, \alpha_{\pi}, \alpha_{y}\right\}
\end{aligned}
$$

The vector $\Psi_{1}$ consists of parameters that we calibrate directly, either because they are pinneddown by steady-state ratios or are known to be weakly identified by the dynamics of DSGE models. After fixing $\Psi_{1}$, we estimate the vector $\Psi_{2}$ using Bayesan methods.

We set $\beta=.9924$, which implies an annual real interest rate of around 3.1 percent. We set $\pi^{*}=1.0074$ to correspond to an annual inflation rate of 3.0 percent. We set $\phi_{x}=0.79$, following Siu (2004). Without reason to suppose that the cash-credit elasticities are different for customer goods, we also fix $\phi_{c}=0.79$. Furthermore, we impose the restriction in estimation that $\sigma_{c}=\sigma_{x}$. We set the Frisch elasticity of labor supply $\nu=2$, a standard number in calibrated models. We set the elasticity of substitution among intermediate goods firms to be $\varepsilon=5$, which is also a standard value in the New-Keynesian literature. We set $\xi$ to be 0.5 . The share of government expenditure is $\Phi_{g}=.2$. We set $\Phi_{a_{1}}=\Phi_{a_{2}}=.01$, to match the roughly two-percent share of advertising in the macroeconomy. Experimentation suggests that, given the parameters $\Phi_{a_{1}}$ and $\Phi_{a_{2}}$, the share of advertising is not identified by the aggregate dynamics of the model. We therefore calibrate the shares of relationship goods to be $\Phi_{N_{1}}=\Phi_{N_{1}}=.19$, so that their total share plus advertising corresponds to half of consumption. We also normalize steady-state hours to be $\bar{l}=0.3$. Finally,

given other parameters, the values of $k_{1}^{f}$ and $k_{2}^{f}$ also have no impact on the steady-state allocations or dynamics in the economy (other than to rescale $a_{i, t}$ and the implied values for $\gamma_{i}$, keeping $\gamma_{i} a_{i, t}$ constant.) Therefore, we can fix them arbitrarily, and set $k_{1}^{f}=k_{2}^{f}=0.5$.

Given the fixed parameters, we estimate the model using Bayesian methods on $Y_{t}=$ $\left[\Delta G D P_{t}, \pi_{t}, R_{t}, \Delta A_{t}^{\text {annual }}\right]$ from 1966Q4 to 2010Q4, with an additional six years of burn-in to initialize the Kalman filter. GDP growth is given by the growth in real per-capita GDP. Inflation is measured using the GDP deflator. The interest rate is given by the three month t-bill rate. And advertising is drawn from the data provided by Douglas Galbi (http://purplemotes.net/2008/09/14/usadvertising-expenditure-data/), collected in part by Robert Cohen, and extended by Hall (2013).

Figure 7 summarizes the prior and posterior density of our estimates. 

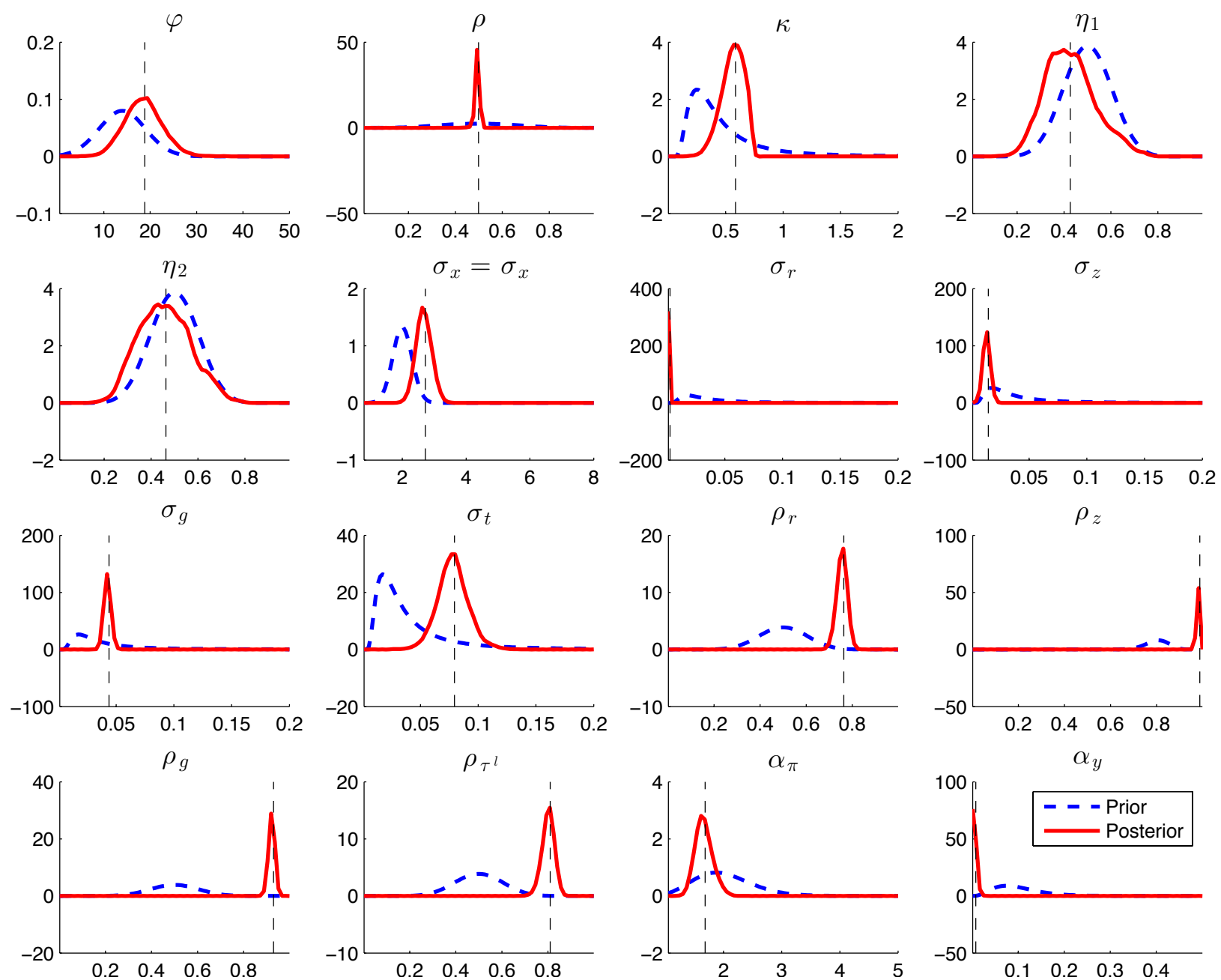

Figure 7: Prior and Posterior Distributions. 


\section{G Ramsey Problem}

The Ramsey problem is to choose state-contingent processes

$\left\{x_{1 t}, x_{2 t}, l_{t}, N_{1 t+1}, N_{2 t+1}, s_{1 t}, s_{2 t}, \theta_{1 t}, \theta_{2 t}, m c_{t}, p_{1 t}, p_{2 t}, \pi_{t}, b_{t}, \tau_{t}^{N_{1}}, \tau_{t}^{N_{2}}, \tau_{t}^{a_{1}}, \tau_{t}^{a_{2}}\right\}$ subject to

1. Aggregate resource constraint

2. Advertising condition for cash goods

3. Advertising condition for credit goods

4. Shopping condition for cash goods

5. Shopping condition for credit goods

6. Aggregate LOM for N1

7. Aggregate LOM for N2

8. Nash pricing equation for cash goods

9. Nash pricing equation for credit goods

10. New Keynesian Phillips Curve

11. Government flow budget constraint, which is

$$
\begin{aligned}
& \left(x_{1 t}+p_{1 t}\left(1+\tau_{t}^{N_{1}}\right) N_{1 t}\right) \pi_{t}+b_{t} \pi_{t}+\tau_{t-1}^{l} w_{t-1} l_{t-1}+p_{1 t-1} \tau_{t-1}^{N 1} N_{1 t-1} \\
& \quad+p_{2 t-1} \tau_{t-1}^{N 2} N_{2 t-1}+\tau^{d} d_{t-1}+\tau^{N K} d_{t-1}^{N K} \\
& \quad=x_{1 t-1}+p_{1 t-1}\left(1+\tau_{t-1}^{N_{1}}\right) N_{1 t-1}+R_{t-1} b_{t-1}+g_{t-1} \\
& \quad+\left[\left(1-k_{1 t-1}^{h}\right) s_{1 t-1}+\left(1-k_{2 t-1}^{h}\right) s_{2 t-1}\right] \kappa \\
& \quad+\tau_{t-1}^{a 1} \gamma_{1} a_{1 t-1}+\tau_{t-1}^{a 2} \gamma_{2} a_{2 t-1}+\tau_{t-1}^{w}\left(1-\tau_{t-1}^{l}\right) w_{t-1} l_{t-1} .
\end{aligned}
$$

A technical issue that arises in the formulation of the Ramsey problem is the dating of the Lagrange multiplier associated with the resource constraint (or, stated equivalently, with the government flow budget constraint). Recall from Appendix (E) that it is the time- $(t-1)$ resource constraint that is implied by the time- $t$ consumer and government flow budget constraints. Because the assumed timing of our model is that the Ramsey planner observes $g_{t}$ and $z_{t}$ before determining time- $t$ allocations and policies, the multiplier associated with the resource constraint is dated $t-1$ - in other words, terms in the Ramsey first-order conditions arising from the time- $t$ 
resource constraint carry a multiplier dated $t$. This formulation of course sounds natural, but we simply mean to point out that because of the assumed timing of markets (namely, asset markets preceding goods and labor markets), care must be taken in writing the Ramsey problem. 


\section{H Social Planner}

The social planner seeks to maximize the lifetime utility of the representative household,

$$
\max E_{0} \sum_{t=0}^{\infty} \beta^{t}\left[u\left(x_{1 t}, x_{2 t}\right)+\vartheta v\left(N_{1 t}, N_{2 t}\right)-h\left(l_{t}+s_{1 t}+s_{2 t}\right)\right]
$$

(in which $s_{t} \equiv s_{1 t}+s_{2 t}$ ), subject to sequences of goods resource constraints

$$
x_{1 t}+x_{2 t}+N_{1 t}+N_{2 t}+g_{t}+\gamma_{1} a_{1 t}+\gamma_{2} a_{2 t}=z_{t} l_{t}
$$

and laws of motion for cash-good relationships

$$
N_{1 t+1}=(1-\rho)\left(N_{1 t}+m\left(s_{1 t}, a_{1 t}\right)\right)
$$

and credit-good relationships

$$
N_{2 t+1}=(1-\rho)\left(N_{2 t}+m\left(s_{2 t}, a_{2 t}\right)\right) .
$$

Denote by $\left\{\phi_{t}\right\},\left\{\mu_{1 t}\right\}$, and $\left\{\mu_{2 t}\right\}$ the sequences of Lagrange multipliers on the sequences of these three constraints, respectively.

The first-order conditions with respect to $x_{1 t}, x_{2 t}, l_{t}, s_{1 t}, a_{1 t}, s_{2 t}, a_{2 t}, N_{1 t+1}$, and $N_{2 t+1}$ are, respectively,

$$
\begin{gathered}
u_{x_{1}}\left(x_{1 t}, x_{2 t}\right)-\phi_{t}=0, \\
u_{x_{2}}\left(x_{1 t}, x_{2 t}\right)-\phi_{t}=0 \\
-h^{\prime}\left(l_{t}+s_{t}\right)+\lambda_{t} z_{t}=0 \\
-h^{\prime}\left(l_{t}+s_{t}\right)+(1-\rho) \mu_{1 t} \cdot m_{s}\left(s_{1 t}, a_{1 t}\right)=0, \\
-\gamma_{1} \phi_{t}+(1-\rho) \mu_{1 t} \cdot m_{a}\left(s_{1 t}, a_{1 t}\right)=0, \\
-h^{\prime}\left(l_{t}+s_{t}\right)+(1-\rho) \mu_{2 t} \cdot m_{s}\left(s_{2 t}, a_{2 t}\right)=0, \\
-\gamma_{2} \phi_{t}+(1-\rho) \mu_{2 t} \cdot m_{a}\left(s_{2 t}, a_{2 t}\right)=0, \\
-\mu_{1 t}+\beta E_{t}\left[\vartheta v_{N_{1}}\left(N_{1 t+1}, N_{2 t+1}\right)-\phi_{t+1}+(1-\rho) \mu_{1 t+1}\right]=0, \\
-\mu_{2 t}+\beta E_{t}\left[\vartheta v_{N_{2}}\left(N_{1 t+1}, N_{2 t+1}\right)-\phi_{t+1}+(1-\rho) \mu_{2 t+1}\right]=0 .
\end{gathered}
$$

For notational convenience, we have used $s_{t}\left(\equiv s_{1 t}+s_{2 t}\right)$ in the displayed FOCs.

\section{H.1 Static Efficiency — Walrasian "Cash" Good / Walrasian "Credit" Good}

Because the Social Planner does not consider the methods by which transactions occur in the decentralized economy, conditions (173) and (174) immediately imply that

$$
\frac{u_{x_{1}}\left(x_{1 t}, x_{2 t}\right)}{u_{x_{2}}\left(x_{1 t}, x_{2 t}\right)}=1 .
$$




\section{H.2 Static Efficiency - Consumption-Labor}

Conditions (174) and (175) imply the standard static efficiency condition between (Walrasian) consumption and labor

$$
\frac{h^{\prime}\left(l_{t}+s_{t}\right)}{u_{x_{2}}\left(x_{1 t}, x_{2 t}\right)}=z_{t}
$$

We could have instead used condition (173) to obtain this result because the Social Planner equates $\lambda_{t}=u_{x_{2}}\left(x_{1 t}, x_{2 t}\right)=u_{x_{1}}\left(x_{1 t}, x_{2 t}\right)$. However, given the setup of the decentralized cash-good/creditgood economy below, expression (183) is a more convenient representation.

\section{H.3 Static Efficiency — Consumption-Search}

The FOCs on $a_{i t}$ and $s_{i t}, i \in\{1,2\}$, imply another (pair of) distinct static efficiency conditions between (Walrasian) consumption and search activity for new customer relationships

$$
\frac{h^{\prime}\left(l_{t}+s_{t}\right)}{u_{x_{2}}\left(x_{1 t}, x_{2 t}\right)}=\frac{\gamma_{i} m_{s}\left(s_{i t}, a_{i t}\right)}{m_{a}\left(s_{i t}, a_{i t}\right)}
$$

For Cobb-Douglas matching and its associated marginals, ${ }^{21}$ static efficiency is characterized by

$$
\frac{h^{\prime}\left(l_{t}+s_{t}\right)}{u_{x_{2}}\left(x_{1 t}, x_{2 t}\right)}=\gamma_{i} \theta_{i t} \frac{\xi}{1-\xi},
$$

in which $\xi$ is the elasticity of the Cobb-Douglas matching function with respect to $s_{i t}$. Define, for Cobb-Douglas matching,

$$
M R T_{x_{2 t}, s_{t}}=\gamma_{i} \theta_{i t} \frac{\xi}{1-\xi}
$$

\section{H.4 Intertemporal Efficiency}

The FOCs on $a_{i t}$ and $N_{i t+1}, i \in\{1,2\}$, imply the (pair of) intertemporal efficiency conditions

$$
\frac{\gamma_{i}}{m_{a}\left(s_{i t}, a_{i t}\right)}=(1-\rho) E_{t}\left[\frac{\beta u_{x_{2}}\left(x_{1 t+1}, x_{2 t+1}\right)}{u_{x_{2}}\left(x_{1 t}, x_{2 t}\right)}\left(\frac{\vartheta v_{N_{i}}\left(N_{1 t+1}, N_{2 t+1}\right)}{u_{x_{2}}\left(x_{1 t}, x_{2 t}\right)}-1+\frac{\gamma_{i}}{m_{a}\left(s_{i t+1}, a_{i t+1}\right)}\right)\right] .
$$

This (pair of) expression(s) for intertemporal efficiency are to be interpreted as the efficient advertising condition(s), or the efficient free entry condition(s) for advertisements. Note that we are purposefully using $u_{x_{2}}\left(x_{1 t}, x_{2 t}\right)$ here, due to the setup of the decentralized cash-good/credit-good economy below.

\footnotetext{
${ }^{21}$ Cobb-Douglas matching has the properties:

1. $m\left(s_{t}, a_{t}\right)=s_{t}^{\xi} a_{t}^{1-\xi}$

2. $m_{s}\left(s_{t}, a_{t}\right)=\xi s_{t}^{\xi-1} a_{t}^{1-\xi}=\xi \theta_{t}^{1-\xi}$

3. $m_{a}\left(s_{t}, a_{t}\right)=(1-\xi) s_{t}^{\xi} a_{t}^{-\xi}=(1-\xi) \theta_{t}^{-\xi}$
} 
Alternatively, we could use the FOCs on $s_{i t}$ and $N_{i t+1}, i \in\{1,2\}$, to obtain an equivalent, alternative, representation of the intertemporal efficiency conditions cast in terms of household utility. This would have the interpretation of efficient searching time conditions on the part of households.

We can similarly define MRS and MRT relevant for intertemporal efficiency. To do so, first restrict attention to the non-stochastic case because it makes clearer the separation of components of preferences from components of technology (due to endogenous covariance terms implied by the expectation operator). As above, we purposefully use $u_{x_{2}}\left(x_{1 t}, x_{2 t}\right)$ because of the setup of the decentralized cash-good/credit-good economy below.

Using the (pair of) expressions immediately above, the IMRT(s) and hence intertemporal efficiency, is (after some algebra) characterized by

$$
\frac{u_{x_{2}}\left(x_{1 t}, x_{2 t}\right)}{\beta u_{x_{2}}\left(x_{1 t+1}, x_{2 t+1}\right)}=\frac{(1-\rho)\left[\frac{\vartheta v_{N_{i}}\left(N_{1 t+1}, N_{2 t+1}\right)}{u_{x_{2}}\left(x_{1 t+1}, x_{2 t+1}\right)}-1+\frac{\gamma_{i}}{m_{a}\left(s_{i t+1}, a_{i t+1}\right)}\right]}{\gamma_{i} / m_{a}\left(s_{i t}, a_{i t}\right)},
$$

for $i \in\{1,2\}$. The interpretation of the right-hand side is the period $t+1$ expected marginal utility gain from consuming non-Walrasian good $i$ plus the expected future savings on advertising for non-Walrasian good $i$.

Formally define, for $i \in\{1,2\}$,

$$
I M R T_{x_{2 t}, x_{2 t+1}}=\frac{(1-\rho)\left[\frac{\vartheta v_{N_{i}}\left(N_{1 t+1}, N_{2 t+1}\right)}{u_{x_{2}}\left(x_{1 t+1}, x_{2 t+1}\right)}-1+\frac{\gamma_{i}}{m_{a}\left(s_{i t+1}, a_{i t+1}\right.}\right]}{\gamma_{i} / m_{a}\left(s_{i t}, a_{i t}\right)} .
$$

\section{H.5 Efficient Allocations}

Efficient allocations are state-contingent functions for $\left\{x_{1 t}, x_{2 t}, l_{t}, a_{1 t}, s_{1 t}, a_{2 t}, s_{2 t}, N_{1 t+1}, N_{2 t+1}, \phi_{t}, \mu_{1 t}, \mu_{2 t}\right\}$ that satisfy: the resource constraint (170), the laws of motion (171) and (172), and all of the FOCs (173) - (181), for given exogenous processes $\left\{z_{t}, g_{t}\right\}$. 